\title{
Dynamically Downscaled Climate Simulations of the Indian Monsoon in the Instrumental Era: Physics Parameterization Impacts and Precipitation Extremes $\mathscr{A}$
}

\author{
YiLing HuO AND W. RichaRd PELTIER \\ Department of Physics, University of Toronto, Toronto, Ontario, Canada
}

(Manuscript received 27 August 2018, in final form 8 November 2018)

\begin{abstract}
The complex orography of South Asia, including both the Himalayas and the Tibetan Plateau, renders the regional climate complex. How this climate, especially the monsoon circulations, will respond to the global warming process is important given the large population of the region. In a first step toward a contribution to the understanding of the expected impacts, a series of dynamically downscaled instrumental-era climate simulations for the Indian subcontinent are described and will serve as a basis for comparison against global warming simulations. Global simulations based upon the Community Earth System Model (CESM) are employed to drive a dynamical downscaling pipeline in which the Weather Research and Forecasting (WRF) Model is employed as regional climate model, in a nested configuration with two domains at 30- and 10-km resolution, respectively. The entire ensemble was integrated for 15 years (1980-94), with the global model representing a complete integration from the onset of Northern Hemisphere industrialization. Compared to CESM, WRF significantly improves the representation of orographic precipitation. Precipitation extremes are also characterized using extreme value analysis. To investigate the sensitivity of the South Asian summer monsoon simulation to different parameterization schemes, a small physics ensemble is employed. The Noah multiphysics (Noah-MP) land surface scheme reduces the summer warm bias compared to the Noah land surface scheme. Compared with the Kain-Fritsch cumulus scheme, the Grell-3 scheme produces an increased moisture bias at the first western rain barrier, whereas the Tiedtke scheme produces less precipitation over the subcontinent than observed. Otherwise the improvement of fit to the observations derived from applying the downscaling methodology is highly significant.
\end{abstract}

\section{Introduction}

Significant effort continues to be expended to understand the impact of the global warming process on the climate futures to be expected in different regions, each of which will experience a unique expression of this global-scale process. Although global climate models (GCMs) are useful tools for the characterization of the large-scale impacts of this process, such models are currently unable to provide information on the regional scale on which differential impacts are expected to be significantly different from those based upon globalmodel-based expectations. This is essentially owing to the fact that regional climate is strongly influenced by small-scale features that are poorly represented in

Supplemental information related to this paper is available at the Journals Online website: https://doi.org/10.1175/JAMC-D-18-0226.s1.

Corresponding author: Yiling Huo, yhuo@physics.utoronto.ca global models, such as land-water contrast and complex and steep topography.

One region in which the impact of topographic gradients is expected to be extreme is South Asia and the India subcontinent as a whole. In this region, the globally unique topographic barrier composed of the Himalayan Mountains and the Tibetan Plateau (TP) poses a significant challenge to our ability to apply numerical models to reconstruct the modern atmospheric circulation and to predict its response to the global warming process, especially on the regional scale. It is especially important that this challenge be met in this region, which to a significant degree is under the control of the TP. The intensity of the summer monsoon circulation strongly affects the population of the region through the agency of monsoon precipitation and especially through the agricultural impacts of drought when the monsoon fails as it did frequently in the late nineteenth century. The subcontinent is dominated by a marked seasonal cycle with relatively dry winters and heavy rain in summersthe South Asian monsoon (Fig. 1). This monsoon 


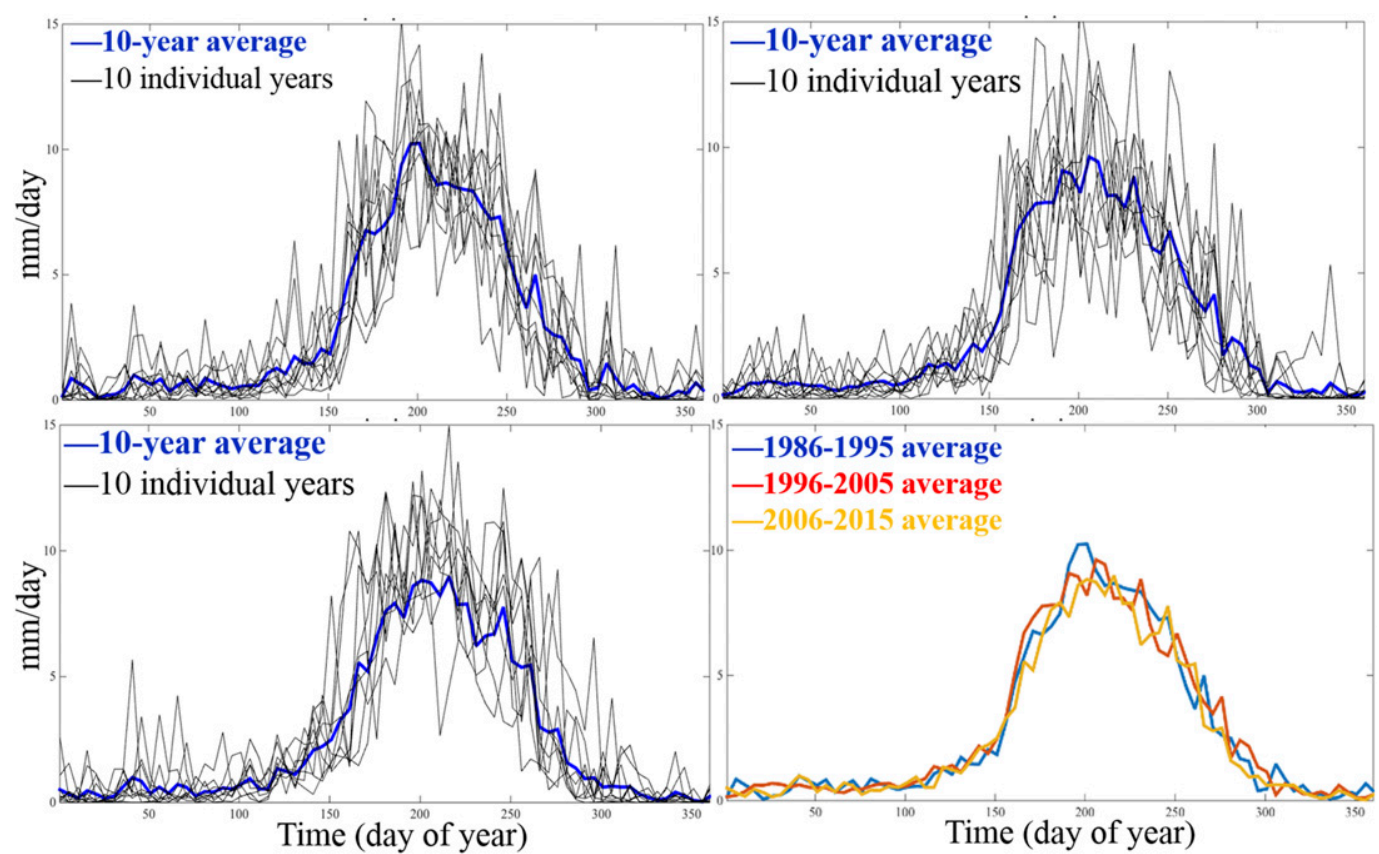

FIG. 1. Annual cycles of precipitation for India $\left(7.5^{\circ}-30^{\circ} \mathrm{N}, 70^{\circ}-87.5^{\circ} \mathrm{E}\right)$ using pentad (5-day average) data for (top left) 1986-95, (top right) 1996-2005, and (bottom left) 2006-15 from the Global Precipitation Climatology Project (GPCP). The black lines show data for the 10 individual years $\left(\mathrm{mm} \mathrm{day}^{-1}\right)$, and the blue lines show the 10-yr average climatology $\left(\mathrm{mm} \mathrm{day}^{-1}\right)$. (bottom right) A superposition of the averages of the annual cycle for the first three individual decades: 1986-95 (blue), 1996-2005 (red), and 2006-15 (yellow).

circulation, according to some, is undergoing gradual changes (Roxy et al. 2015; Loo et al. 2014) as a result of rapid warming due to increasing atmospheric greenhouse gas concentrations. Owing to the dependence of the strength of the monsoon on the temperature differences between the ocean and the land (e.g., Webster et al. 1998), the differential heating between the Indian Ocean (Roxy et al. 2014) and the subcontinent of India (Roxy et al. 2017) is especially important in deciding the direction and extent of the future changes of the Indian monsoon. By analysis of a daily rainfall dataset, Goswami et al. (2006) have suggested the existence of significant rising trends in both the frequency and the magnitude of extreme rainfall events as well as a significant decreasing trend in the frequency of moderate rainfall events over central India during the monsoons from 1951 to 2000. As a result of these two opposite trends, the seasonal mean rainfall exhibits no significant secular variation. Kripalani et al. (2003), on the other hand, also analyzed observed data for the 131 years (1871-2001) and found no clear evidence to suggest that the strength and variability of the Indian monsoon rainfall is affected by the global warming process, although the first 30 years of this period were characterized by multiple failures of monsoon occurrence. However, Verma et al. (2018) used daily meteorological data for the Upper Gangetic Plain (UGP) in India to show that there was a decline in both monthly and annually averaged rainfall during the period of 1986-2015 as compared to 1956-85. In general, the stability of Indian monsoon rainfall over the past century has remained a puzzle against a backdrop of rising global surface temperature.

The TP as a factor in the Indian monsoon has long been considered to contribute to driving this thermally direct circulation by leading to the more rapid heating of the air above it than in surrounding lower-elevation regions and thus contributing to the formation of a surface low pressure center (Flohn 1968). One frequently invoked piece of evidence in support of this viewpoint is the fact that removing all regional elevated orography in a global coupled climate model strongly reduces monsoon intensity and northward extent (e.g., Yasunari et al. 2006). By employing proxy data constraining winds and rainfall under past conditions, it has also been argued that the onset of strong Southeast Asian monsoons was caused by the tectonic uplift of the TP that began approximately 50 million years ago (An et al. 2001). Bolin (1950) and Yeh (1950), on the other hand, suggested that the Tibetan Plateau more importantly acts in such a way as to dynamically split the westerlies into two branches under winter conditions. The early numerical simulations performed by Charney and Eliassen (1949) also focused 
upon the action of the mechanical forcing associated with large-scale topography on the formation of mean-flow Rossby-wave-related troughs and ridges in the midlatitude westerlies. Of course, the Tibetan Plateau also acts to prevent dry and cold extratropical air from "ventilating" the moist and warm tropics and subtropics (Chou et al. 2001; Prive and Plumb 2007b). The Tibetan Plateau is therefore currently understood to exert both profound thermal and dynamical influences on the monsoon circulations, which deliver water to more than 1 billion people in socially vulnerable agricultural economies in East Asia as well as India. Temporal and spatial variability in this monsoon circulation can result in either severe droughts when the monsoons fail or floods when its strength is especially extreme with profound socioeconomic impacts in either case (Cook et al. 2010).

It is not only the high topography of the TP that plays a role in the monsoon circulation. The more localized coastal mountains in western India and in the northeast are also known to play a role in the distribution and intensity of monsoon precipitation. Xie et al. (2006) in particular employed Tropical Rainfall Measuring Mission (TRMM) Precipitation Radar (Kummerow et al. 2000) and Special Sensor Microwave Imager (Wentz 1997) rainfall data to demonstrate that the Western Ghats are an important organizing agent in anchoring monsoon convection centers to the windward side of the subcontinent, even though these mountains are narrow in width and modest in height $(<1 \mathrm{~km})$. They are also poorly represented in global climate models implying that dynamical downscaling may contribute significantly to the improvement of the representation of the monsoon in this coastal region.

To fill the gap between the low resolution of GCMs and the need for high-quality climate information on regional scales, this study employs the dynamical downscaling pipeline described in Gula and Peltier (2012), d'Orgeville et al. (2014), and Erler et al. (2015) in which a regional climate model is forced with output from a GCM at the lateral boundaries in order to downscale climate simulations for the subcontinent of India. The goal of the present study is to apply and validate this state-of-the-art dynamical downscaling pipeline in order to obtain highspatial-resolution simulations of Indian summer monsoon precipitation as well as its extremes under modern climate conditions. These results will later serve as a basis for comparison with forward projections of the influence of the global warming process on Indian monsoon phenomenology.

Since GCMs do not track the historical evolution of weather, each model integration is to be interpreted as completely independent. The differences between such independent realizations are understood to be associated with the chaotic nature of the climate system (Flato et al. 2013) and are referred to as involving the action of internal variability. Consequently, at scales that are dominated by this impact, direct comparison of simulations with observations is meaningless. Regional climate models driven by GCMs are also affected by this problem, and thus only comparisons of long-term averages and the statistical distributions of physical properties obtained from such long integrations and/or multiple realizations are meaningful (Deser et al. 2012).

A high degree of natural variability combined with a scarcity of observational records of sufficient length also makes the characterization of precipitation extremes with decadal return periods more difficult. To overcome this problem, this study uses a pooling technique developed by Erler and Peletier (2016) that combines data from different stations (or grid points at station locations) based on the similarities of the annual cycle of their climate. This is a major difference between the results obtained in our analyses from the results reported in many earlier studies, whose estimates of the probability distribution of various climate parameters were obtained with a gridpoint-based method. Our approach will be seen to be similar to regional frequency analysis (RFA; Hosking and Wallis 1997) in that samples from different sites are combined (pooled), but the method does not rely upon the assumption that the distribution shapes of the samples are statistically homogeneous, which can be problematic in regions such as India. Instead, this problem is addressed by applying a clustering algorithm based on average climatic characteristics of the stations. This study then uses pooled data from station clusters to analyze the extreme values. Since stations from the same cluster share a similar climatology, their climates can be considered to be drawn from the same parent distribution.

Section 2 of this paper, which follows, provides a brief review of previous work on the application of downscaling methods to the improvement of understanding of the Indian monsoon. Section 3 describes the details of the dynamical downscaling methodology employed in this study as well as the observational datasets used as a basis for verification. In addition, the clustering algorithm employed for pooling and the fundamentals of extreme value analysis are also described in this section. In section 4, validation against historical observations of the seasonal mean is discussed, before results from the extreme value analysis are presented in section 5. Section 6 deals primarily with differences between the 4 members of the WRF physics ensemble that we have designed as an aid to understanding the influence upon our results of the representations we employ for unresolved physical processes. A summary of our primary conclusions is offered in section 6 . 


\section{Simulations of the Indian monsoon using dynamical downscaling: A review of previous contributions}

It has already been clearly demonstrated that regional climate simulations can be greatly improved simply by increasing the resolution within target domains. For example, Shi (2010) downscaled the results of a global simulation over East Asia obtained using the Regional Climate Model, version 3 (RegCM3), developed by the Earth System Physics Group at the Abdus Salam International Center for Theoretical Physics (Hostetler et al. 2011), and found that the downscaled results delivered by RCMs were more realistic climatologically compared with those delivered by global GCM. Ji and Kang (2013) have also performed simulations at 10-km resolution over the TP itself, using the Regional Climate Model, version 4 (RegCM4), driven by a global model referred to as the Beijing Climate Center Climate System Model, version 1.1 (BCC_CSM1.1). They found that the temperature simulations delivered by their implementation of a doubly nested configuration better reflected the observations on the Plateau compared to those from the global GCM, but also that precipitation intensity in the mountains, such as the Himalayas and Hengduan Mountains was significantly overestimated. They suggest that estimates of the quality of the model performance are as significantly influenced by the uncertainties of observations as by the choice of model parameterization schemes that are employed to represent precipitation processes. Guo and Wang (2016) have even more recently performed simulations at $50-\mathrm{km}$ resolution for a 20-yr period over China, using the Weather Research and Forecasting (WRF) Model, and report improved performance even when compared with a very-fine-resolution global GCM (at approximately $0.5625^{\circ}$ resolution) in terms of the climatology and intermonthly variation of precipitation.

In a more recent application of the regionalization of a global climate simulation for the Indian subcontinent, Rupa Kumar et al. (2006) downscaled the output from a high-resolution global model (HadAM3H) by using a regional climate model, known as Providing Regional Climates for Impacts Studies (PRECIS) at $0.44^{\circ} \times$ $0.44^{\circ}$ resolution. Evaluation of the historical simulation (1961-90) has shown that features on finer scales are better resolved in the RCM than in the GCM, most likely because of improved resolution of the topography. The biggest improvement is that the spatial patterns of summer monsoon precipitation, especially the peak intensity west of the Western Ghats, are better represented in the RCM. Precipitation intensity biases over some other regions are primarily caused by similar biases in the driving GCM. Tiwari et al. (2016) employed an optimized configuration of the Regional Climate Model (RegCM, at $45-\mathrm{km}$ resolution), driven by a global spectral model (a T80-resolution model with horizontal resolution of $\sim 1.4^{\circ}$ ) over north India for 28 years (19822009). They found a significant improvement in the ability of the regional model to reproduce the spatial distribution of monsoon precipitation compared to results obtained from the T80-resolution global model. They also demonstrated that this improvement resulted from an improved representation of vertical velocity, moisture transport, convective heating rate, and temperature gradient. Moreover, orography in the high-resolution $\mathrm{RegCM}$ was shown to improve the precipitation simulation in the region where sharp orographic gradients play an important role in wintertime precipitation processes. Varikoden et al. (2018) have further assessed the dynamical downscaling of summer monsoon rainfall over three regions: the Western Ghats (WG), central India (CI), and the northeastern region (NER) for the historical period from 1951 to 2005 based on six Coordinated Regional Climate Downscaling Experiment (CORDEX) results for the South Asia (SAS) region. They found an overall reduction of dry bias in rainfall across these regions of the Indian subcontinent in most of the downscaled CORDEX-SAS models and in their ensemble mean as compared to that of the driving GCMs, especially in complex topographical regions such as the WG. However, the "added value" in the CORDEX-SAS simulations for the large CI region, which is dominantly influenced by synoptic-scale processes, is not clear. It must also be noted that, although increased resolution significantly improves the representation of local climatic features as demonstrated in these studies, the errors, especially the cold bias between RCMs and observations, were still obvious in the TP (Zhang et al. 2005; Shi et al. 2011). In the work reported herein, we will extend these recently reported results by further increasing the spatial resolution to which we downscale the global model results, but we will also focus on the accuracy of these results insofar as the ability to reproduce the observed probability distribution of extreme rainfall events is concerned, a topic on which nothing has been previously published using the modern downscaling methodology.

\section{Models, simulations, and analytical methods}

\section{a. Dynamical downscaling simulations}

This study utilizes the WRF Model (Skamarock and Klemp 2008) as the regional climate model. WRF is a latest nonhydrostatic regional model that is often now 
being employed for long-term climate simulations (e.g., Fita et al. 2010). The simulations in the current study have been performed utilizing WRF, version 3.4, with the following atmospheric physics parameterization configurations: the Rapid Radiative Transfer Model for global coupled models (RRTMG) scheme for short- and longwave radiation (Iacono et al. 2008); the Mellor-Yamada Nakanishi and Niino, level 2.5, scheme for planetary boundary layer parameterization (Nakanishi and Niino 2009); the WRF single-moment 6-class (WSM6) scheme for microphysics (Hong and Lim 2006); either the Noah land surface model (LSM) (Tewari et al. 2004) or the Noah LSM with multiparameterization (MP) options (Niu et al. 2011) for land processes; and the Kain-Fritsch (KF) cumulus scheme (Kain 2004), the Grell 3D ensemble cumulus scheme (Grell and Dévényi 2002), or the Tiedtke cumulus scheme (Tiedtke 1989) for cumulus parameterization. Table 1 summarizes the specific four different mixtures of physics parameterizations to define the different members of the physics ensemble, the results for which will form a focus of the present analysis: the first ensemble member can be compared to the second to investigate the effect of land surface models, and the third and fourth ensemble members can be compared for the impact of the choice of cumulus schemes. We are interested in the impact of the choice of cumulus schemes because the South Asian summer monsoon is driven by organized large-scale convection, and the simulation of monsoon precipitation has been found to be sensitive to the cumulus parameterization schemes used in the RCMs (Mukhopadhyay et al. 2010; Srinivas et al. 2013; A. Raju et al. 2015). Meanwhile, in regional models, the LSM plays an important role in modulating the surface fluxes of momentum, heat, and moisture between the land surface and atmosphere and the changes in land surface fields have a large impact on temperature and precipitation patterns (Pielke 2001; Srinivas et al. 2015). Thus, Noah-MP, which is an extended version of the default Noah LSM in WRF and has more configuration and parameterization options, including a three-layer snow model, is also applied in the hope that it would help reduce the temperature bias we found in our control run.

A unique Community Earth System Model, version 1 (CESM1), simulation has then been dynamically downscaled using these four different physics configurations in the WRF Model, resulting in the four members of the physics ensemble with the same initial conditions. This CESM1 simulation was driven by both anthropogenic and natural forcing and covers a historical period from 1850 to 2005. CESM is a state-of-the-art phase 5 of the Coupled Model Intercomparison Project (CMIP5) GCM and is a fully coupled global climate model with interactive atmosphere, land, ocean, and sea ice components [see Gent et al. (2011) for a complete
TABLE 1. Simulations of the physics ensemble and their selected parameterization.

\begin{tabular}{cll}
\hline \hline Simulation & Cumulus scheme & Land model \\
\hline 1 & Kain-Fritsch & Noah LSM \\
2 & Kain-Fritsch & Noah-MP \\
3 & Grell-3 & Noah LSM \\
4 & Tiedtke & Noah LSM \\
\hline
\end{tabular}

description], and the nominal resolution of the standard configuration, which was employed here, is approximately $1^{\circ}\left(\approx 100 \mathrm{~km}\right.$ at $\left.50^{\circ} \mathrm{N}\right)$. Six-hourly output from this unique CESM1 simulation is employed to force the historical WRF ensemble with four independent members (Table 1), and each member has been integrated for 15 years from 1980 to 1994.

The downscaling procedure uses the two-step nesting method described in Gula and Peltier (2012) and d'Orgeville et al. (2014). In this procedure, a nested configuration is employed consisting of an outer domain and an inner domain. Compared with Gula and Peltier (2012) and d'Orgeville et al. (2014), the major difference is the domain setting. The outer domain in this study covers most of Asia and the Indian Ocean at a resolution of $30 \mathrm{~km}$, while the inner domain covers most of the Indian subcontinent south of the TP, as well as parts of the surrounding areas, at a resolution of $10 \mathrm{~km}$. The representation of the topography and outlines of the outer and inner domains are shown in Fig. 2. As in Gula and Peltier (2012) and d'Orgeville et al. (2014), the lateral boundary conditions at the outermost grid point in WRF were prescribed from CESM, and the WRF solution over the adjacent nine grid points was nudged toward the conditions in CESM using the method of Davies and Turner (1977), with higher nudging coefficients for grid points that are closer to the WRF outerdomain edges. To prevent drift of the large-scale fields in the interior of the domain, spectral nudging (MiguezMacho et al. 2004) toward the CESM solution was applied above the boundary layer at horizontal scales larger than approximately $2000 \mathrm{~km}$.

\section{b. Observational datasets}

Daily station observations and monthly gridded datasets are employed for validation of the downscaled climate reconstructions. The gridded precipitation and temperature datasets used here to validate the simulations is that of the Climate Research Unit (CRU) at the University of East Anglia (Harris et al. 2014). It provides multivariate monthly time series that have been designed specifically for long-term climate studies. The data are available at $0.5^{\circ}$ resolution over the global land area (excepting Antarctica) from 1901-2012 and our analysis will be based upon version TS 3.2. To compute differences 
topography in WRF d01

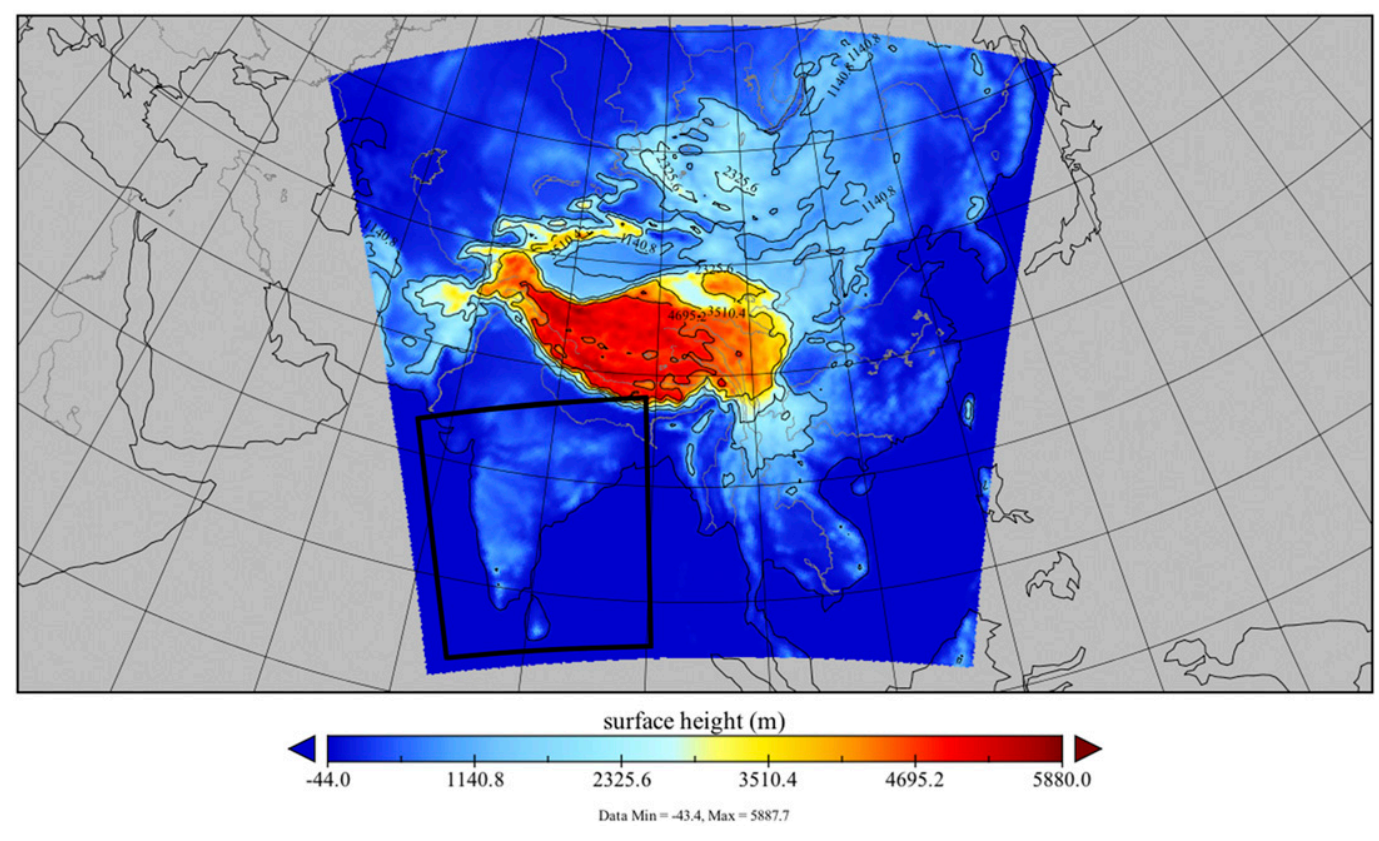

FIG. 2. Topography contours (black) and outline of the outer and inner WRF domains, as well as major rivers and lakes (gray).

between model results and the observations, the observational datasets have been regridded onto the grid of the model from which the climate simulation is taken.

For the purpose of extreme value analysis, the Global Historical Climatology Network (GHCN)-Daily station database (Menne et al. 2012) is used for daily precipitation. This dataset provides daily climate data over global land areas and was designed for a variety of applications, including weather and climate studies such as the analysis of heavy rainfall event frequency, and heat wave intensity and duration. Quality assurance (QA) checks are routinely applied to the dataset, but the data are not homogenized to account for artifacts associated with the various eras in reporting practice at any particular station (i.e., for changes in systematic bias).

The latest European Centre for Medium-Range Weather Forecasts (ECMWF) interim reanalysis (ERA-Interim; hereafter, ERA-Int) (Dee et al. 2011) is also employed as a basis for calculating surface air moist static energy in section 6. ERA-Int uses a spectral T255 atmospheric model with 60 vertical levels, with the Tiedtke (1989) cumulus convection parameterization, and gridded output is available at a horizontal resolution of $0.75^{\circ}$ latitude $\times 0.75^{\circ}$ longitude.

\section{c. Station clustering}

This section introduces the analytical framework employed in the analysis of precipitation extremes presented in this article. The same framework has also been employed previously by Erler and Peltier (2016) to analyze precipitation extremes in historical observations over western Canada. As commented above in section 1 , it is desirable to pool station data in order to increase the amount of data from which the parameters of the probability distribution are estimated so as to improve the accuracy of the inferred rainfall event frequency as a function of severity. However, combining all stations from the subcontinent into a single cluster would be unreasonable because significant variations of climate occur over the landmass.

To group stations with a similar climate and seasonal cycle, this study has used the $k$-means algorithm (Hartigan and Wong 1979), which is popular for cluster analysis. Using an iterative refinement technique, the $k$-means algorithm partitions observations into an a priori determined number of clusters in which each observation belongs to the cluster with the nearest mean. In the first step of the clustering process, each station was represented by a feature sequence composed of the climatological seasonal cycle of monthly mean precipitation measured at the station. A total of 58 stations result in 58 twelve-dimensional vectors, or a $58 \times$ 12 matrix. In the second step, principal component analysis was applied to reduce the dimensionality of the station sequences, and only the three leading empirical orthogonal functions (EOFs) were retained, which 


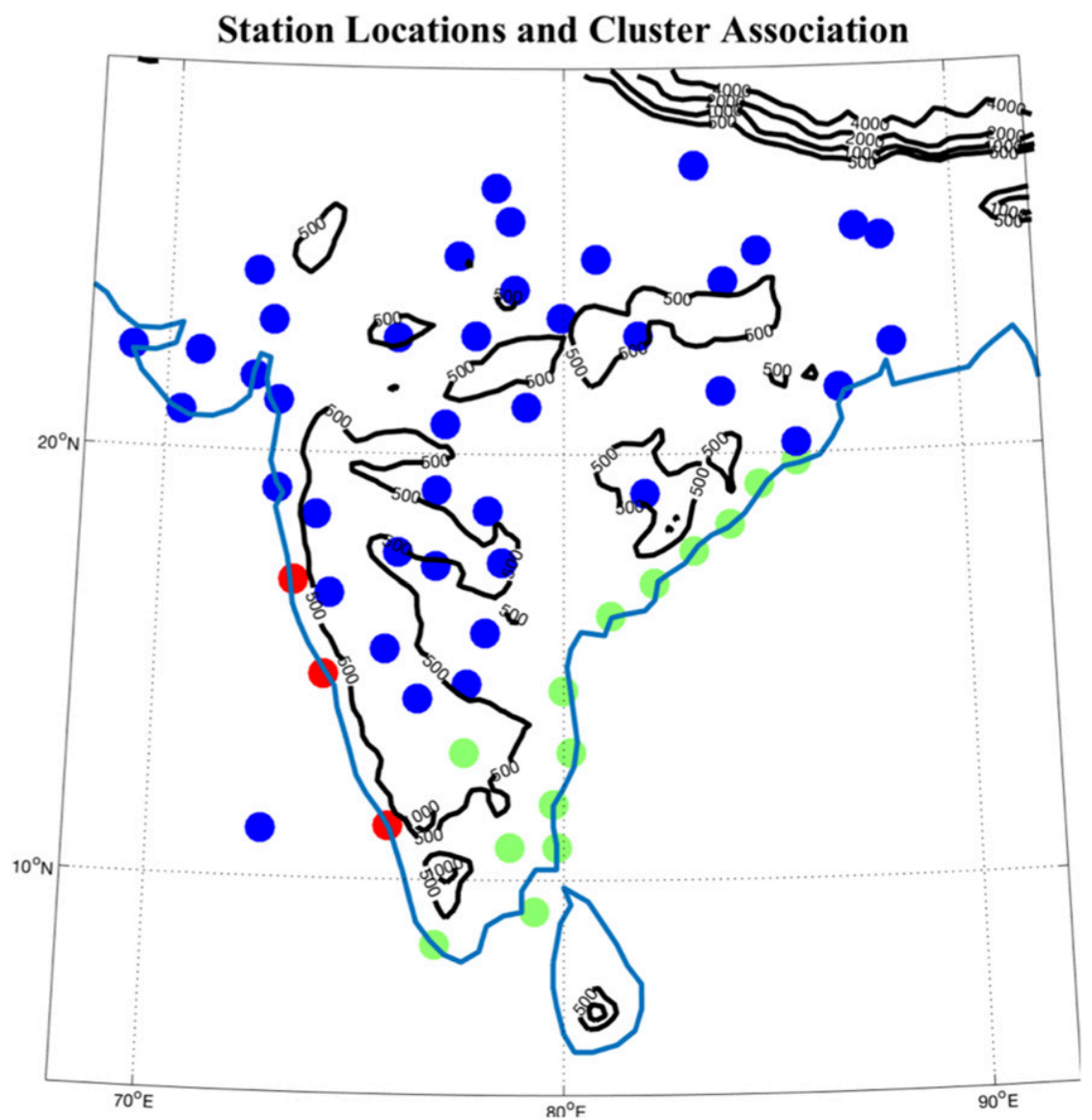

FIG. 3. Station locations with topography contours (black; 30-km resolution). The marker color indicates station cluster association: clusters 1 (blue), 2 (green), and 3 (red).

combined explain $99.9 \%$ of the total variance. This step changes the $58 \times 12$ matrix in the first step into a $58 \times 3$ matrix or 58 three-dimensional vectors. In the last step, the $k$-means algorithm is applied to these $58 \mathrm{vec}$ tors in order to assign them into different clusters. The result of the clustering algorithm is found not to be sensitive to the number of EOFs used, as long as the first three are included. The locations of stations and their cluster associations are shown in Fig. 3. A total of three clusters were identified through application of the clustering algorithm. This number was chosen so that a minimum of 200 combined years of data is available for each cluster as a basis for defining the probability distribution of daily rainfall. Notable is the fact that the three clusters consist of stations from central India and stations from the east and west coasts. The fact that the formal cluster algorithm produces clusters that might have been assumed on a priori physical grounds is reassuring of its validity.

The three clusters are defined on the basis of a total of 58 stations. Cluster 1 (41 stations) covers central and south India, cluster 2 (14 stations) represents the east coast, and cluster 3 (3 stations) represents the west coast and the Western Ghats. Results will be presented separately for each cluster, but the data will be aggregated over all of the stations within a given cluster.

\section{d. Extreme value analysis}

Extreme value analysis deals with the extreme deviations from the mean of individual probability distributions, and includes two major approaches (Coles 2001). One is the so-called peak-over-threshold approach, which only considers data that are viewed as extreme on a priori grounds (beyond a fixed threshold). The return values of extremes are determined from a generalized Pareto (GP) distribution that is fitted by the method of maximum likelihood to the distribution of the time series of the extreme data. This was the approach taken by d'Orgeville et al. (2014) in their analysis of the return times of extreme precipitation events in the Laurentian Great Lakes region of eastern North America. The other approach is the one that is employed here, which is based on the 
generalized extreme value (GEV) distribution and uses block maxima (maxima taken over a fixed number of independent and identically distributed random variables). This method has been employed in Erler and Peltier (2016) in their analysis of extreme precipitation events over a topographically complex region of western North America.

To increase the number of data points that constrain the distribution fits, data from different stations within a cluster are pooled and a single GEV distribution is fit to each cluster. Since the station clusters have been constructed based on climatic similarity, the pooling region is naturally homogeneous, allowing a reasonable distribution fit to the combined data. Furthermore, since the impact of longterm climate variability (such as that due to ENSO) will also lead the parent distribution of extreme events to vary slowly over time, some degree of spatial variation in a single station cluster is also acceptable. For the purpose of comparison of the model-derived results to observations and for the estimation of extremes, we will also employ bias correction of the distribution mean and the temporal variability of the model output using the following formula: $T_{\mathrm{BC}}=\bar{O}+\left(\sigma_{O} / \sigma_{T_{\text {raw }}}\right) \times\left(T_{\text {raw }}-\bar{T}_{\text {raw }}\right)$, where $O$ represents observations; $T_{\text {raw }}$ represents raw model output; $T_{\mathrm{BC}}$ represents bias-corrected model output; and $\sigma_{T_{\mathrm{raw}}}$ and $\sigma_{O}$ represent the standard deviation of the daily model output and observations, respectively (Hawkins et al. 2013). As a result, the distribution mean and the temporal variance of the bias-corrected time series are adjusted to conform to the observations.

\section{Results: Validation of downscaled results against historical observations}

\section{a. The mean climate}

In this section, we will present an overview of the validation of our downscaled results against historical observations for seasonal averages of temperature and precipitation over the Indian subcontinent in order to provide a basis for the understanding of model biases. Note that all numerical biases reported in this section will refer to averages over the area of the inner WRF domain excluding the oceans. The statistical significance of the temperature differences between the observations and the simulations is evaluated using the Student's $t$ test, and the $p$ values are listed in the bottom-left corners of each panel in the figures, which show the biases. If the $p$ values from the $t$ test are smaller than 0.05 , the differences between the simulations and observations are statistically significant at the 0.05 level. Also note that the observational datasets that we employ for validation purposes may contain errors and biases themselves and so allowance must be made for this.
Absolute temperature bias measured against the observational dataset for the annual mean (top) as well as the summer (middle) and winter (bottom) seasonal averages are shown in Fig. 4. The CESM result is shown in Fig. 4 (left), and the outer and inner domains of WRF simulations (Fig. 4, center and right, respectively) are also shown. The differences were computed on the native grid of each model output; the observations have been reprojected and resampled for this purpose. Note that gridded CRU observational datasets only cover land areas, and thus no validation was performed over the ocean. It is evident that the temperature biases are strongly dependent on the season and vary strongly between models. A general trend visible in both CESM and WRF is a consistent bias toward lower temperatures in winter over the entire subcontinent. Beyond that, CESM shows a strong cold bias east of the Western Ghats in summer, while the WRF simulations show a slight warm bias so that the cold bias of the global model has been somewhat overcorrected by the regional model. Integrated over the land area of the inner WRF domain and all seasons, the annual-mean temperature bias in WRF $\left(-1.2^{\circ} \mathrm{C}\right.$ for the outer domain and $-1.3^{\circ} \mathrm{C}$ for the inner domain) is primarily caused by a significant cold bias in winter $\left(-3.6^{\circ} \mathrm{C}\right.$ for the outer domain and $-3.1^{\circ} \mathrm{C}$ for the inner domain) and this cold bias is partially compensated by the warm bias in summer.

Indian monsoon rain is highly organized in space: in a 15-yr climatology based on CRU observations, distinct centers are found in the eastern Arabian Sea and Bay of Bengal (Fig. 5, top left). Figure 5 also shows averaged summer precipitation climatologies for CESM (top right) and the inner and outer WRF domains (bottom). To facilitate the comparison with the observations, model data are only shown over land. The spatial pattern in both models and observations is strongly dominated by orographic forcing superimposed on a large-scale gradient away from the coast. This results in very high precipitation rates west of the coastal mountain ranges on the west coast and to a lesser extent in the Western Ghats themselves and much lower precipitation rates in their rain shadows over the interior of the subcontinent. Generally, the 15-yr-average summer rainfall from CESM agrees with observations, but it differs significantly from observations in detail. These detailed differences reveal the mechanisms responsible for creating the convection centers that dominate the Indian monsoon. Warm moist air from the southwest is forced to rise upon meeting the west coastal mountains, leading to strong convection on the windward side of the region of enhanced orography. Particularly, in the western part of the subcontinent, a narrow rainband lies along the Indian coast west of the Western Ghats, a feature well 

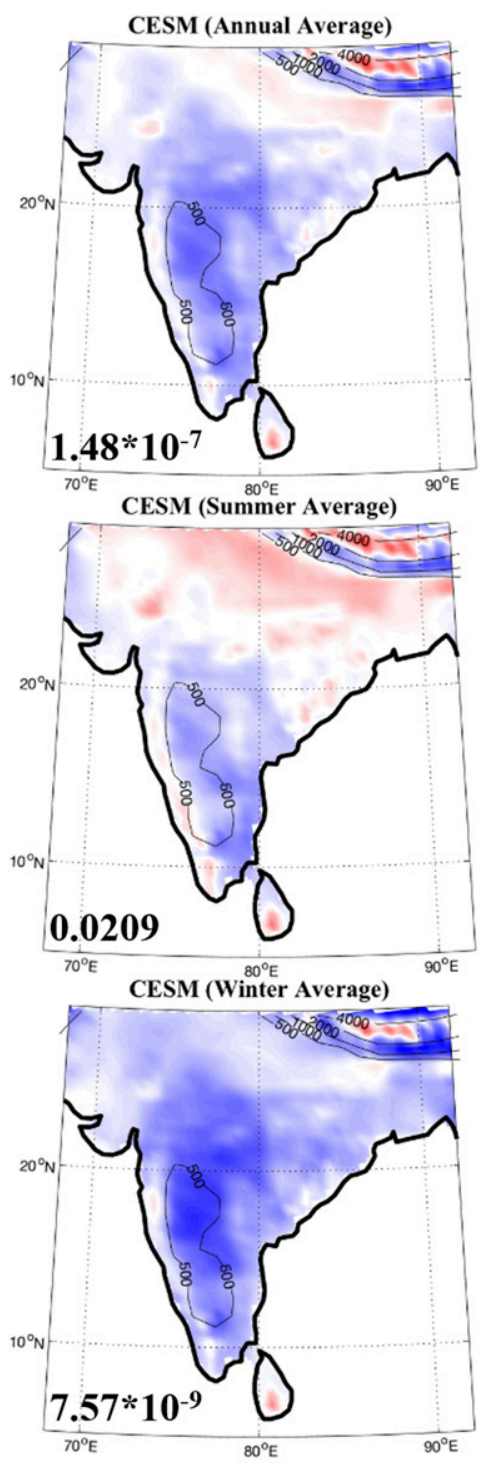

Averaged 2-m air temperature differences
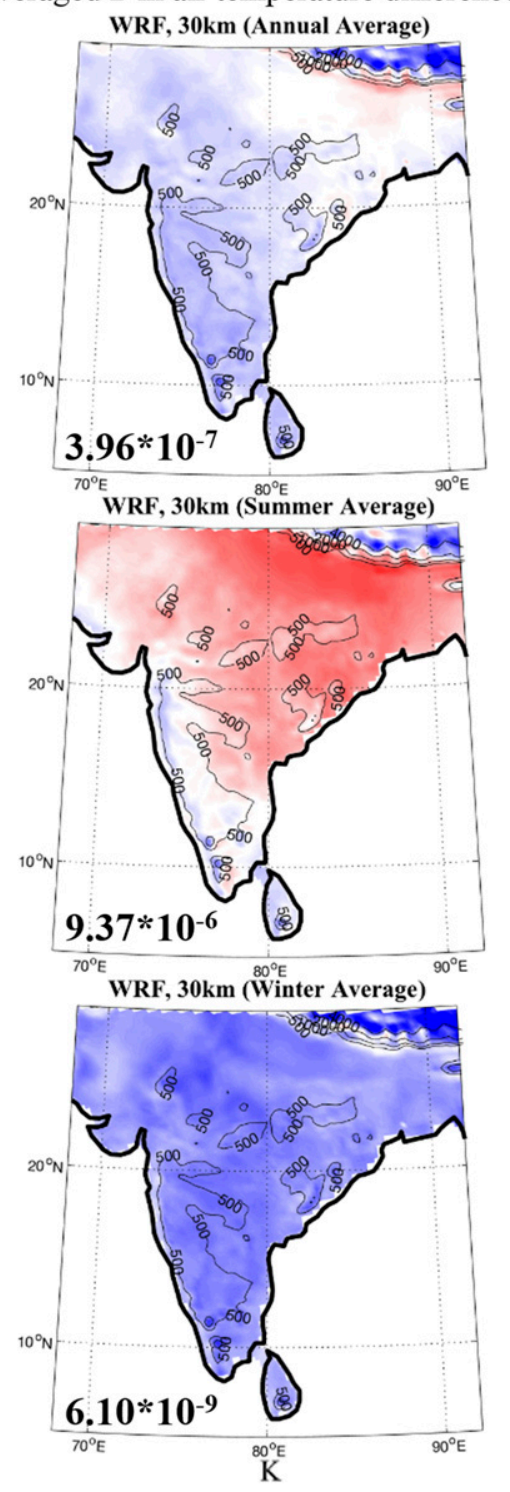
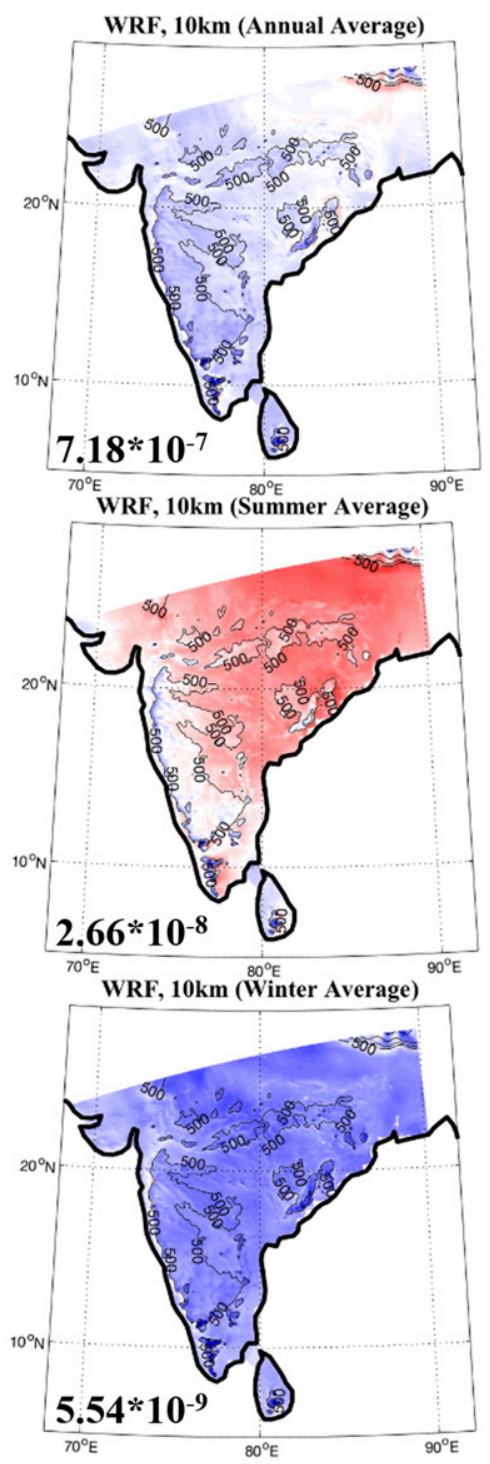

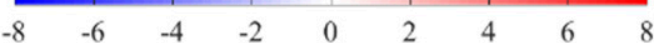

FIG. 4. (top) Annual-mean, (middle) summer, and (bottom) winter differences of 2-m air temperature with respect to the CRU observational dataset, averaged over 15 years: (left) CESM, (center) outer WRF domain $(30 \mathrm{~km})$, and (right) inner WRF domain (10 km). The $p$ values of the $t$ test are shown in the bottom-left corners of each panel, and the topography contours ( $\mathrm{m}$ ) of each model are also shown in the background.

captured in WRF simulations with both $30-$ and $10-\mathrm{km}$ resolutions. However in the CESM global model, this rainband is significantly muted, being both significantly broader and of much reduced amplitude. The strong convection core located on the western coast of the Bay of Bengal is created when the northeastern warm moist wind meets the narrow mountain ranges of Arakan Yoma in the northern bay, which is well captured in the WRF simulation at $30-\mathrm{km}$ resolution (it is outside the WRF inner domain) but is missing entirely in the CESM simulation. Clearly, the peak rainfall intensities within the coastal mountains as well as the rain shadow effect in their lee are strongly underestimated by the low-resolution CESM simulation. Thus, the representation of orographic precipitation is strongly dependent on the model resolution: the rain shadow east of the Western Ghats is almost nonexistent in CESM but significantly improved in WRF at both 30- and 10-km resolutions. 

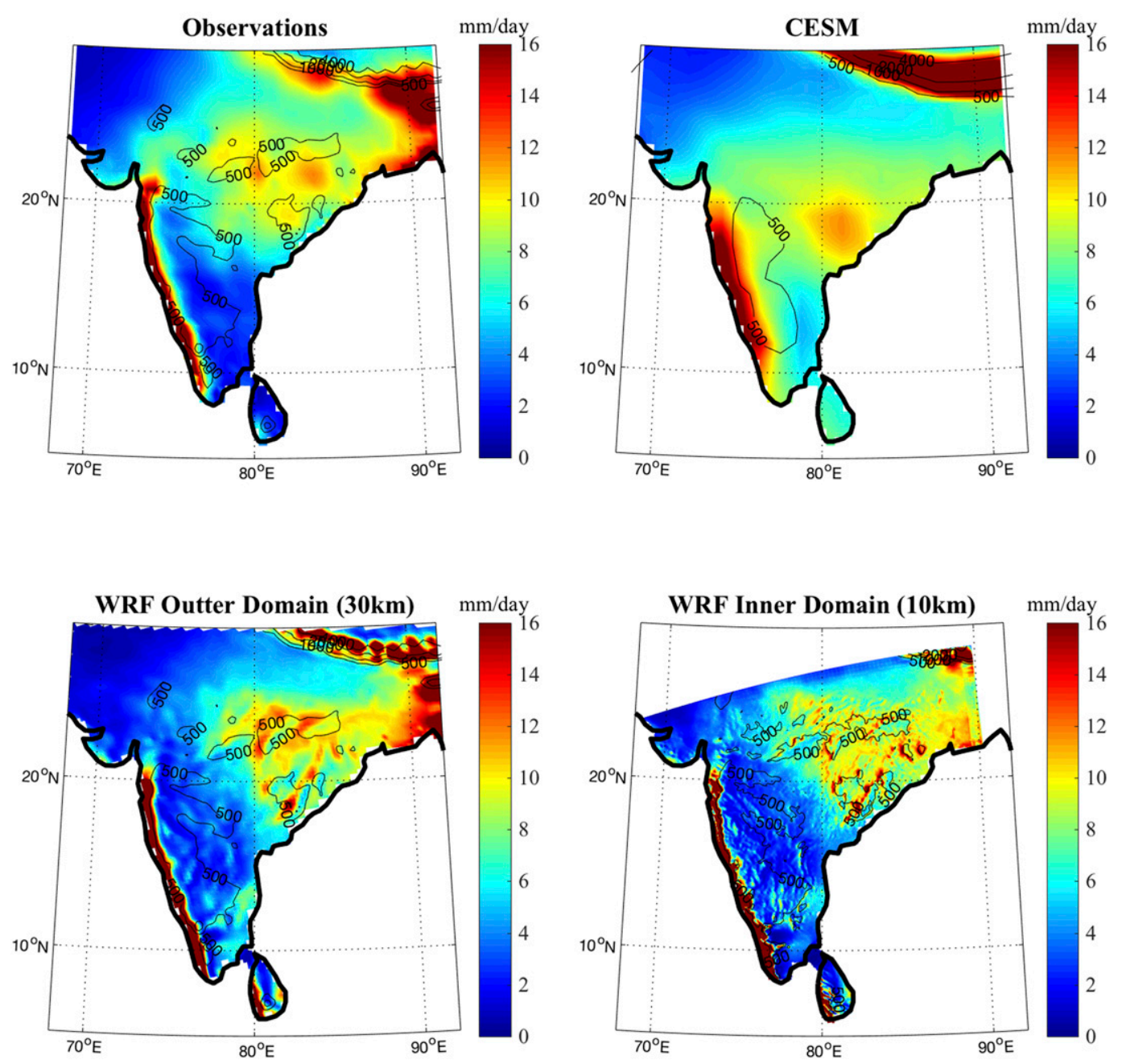

FIG. 5. Summer total precipitation averaged over 15 years (1980-94): (top left) the CRU observational dataset and (top right) the CESM; (bottom left) the outer WRF domain and (bottom right) the inner WRF domain. The topography contours $(\mathrm{m})$ are also shown in the background.

The absolute precipitation bias in summer and winter is shown in Fig. 6. In south India, CESM results are characterized by a consistent overestimation in all seasons except at the rain barrier provided by the Western Ghats in summer, where precipitation is underestimated. CESM also underestimates the amplitude of the seasonal cycle of precipitation in central India: there is a consistent dry bias in summer and a wet bias in winter; these opposite and compensating biases in summer and winter precipitation rates result in the relatively good match in the annual precipitation field. Evidently, the bias in winter is significantly stronger in CESM than in WRF, presumably because of the poor representation of topography. Comparing results from the inner and outer domains of WRF, the reduction of bias is primarily concentrated in the mountains in central India known as the Satpura Range and southeastern region of the domain, where the topography is relatively complex. Averaged over the land area in the WRF inner domain, the summer precipitation bias is $27 \%$ and $13 \%$ in the WRF outer and inner domains, respectively, so that the further downscaling from 30 to $10 \mathrm{~km}$ has had a very positive effect in reducing the bias. The $p$ values from the $t$ test are larger than 0.05 for the WRF outer and inner domains in summer, indicating that the precipitation differences between the regional simulations and the observations averaged over India are not statistically significant. On the contrary, CESM has a statistically significant precipitation bias in summer ( $p$ value $=0.001)$, which confirms the improvement of fit 

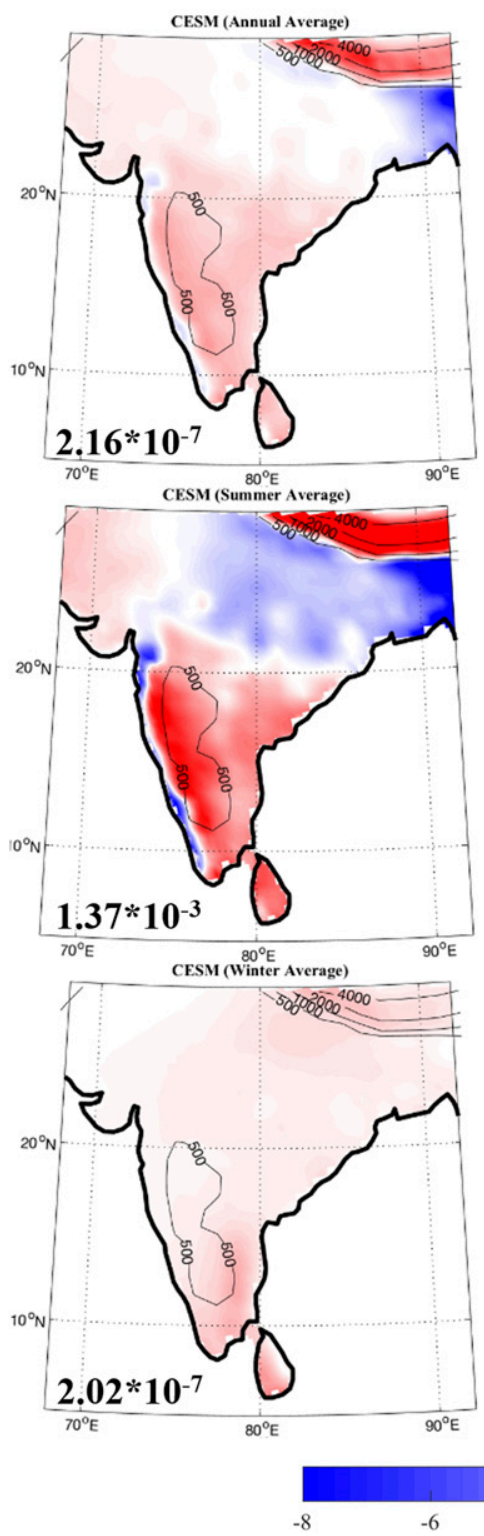

Averaged total precipitation rate differences
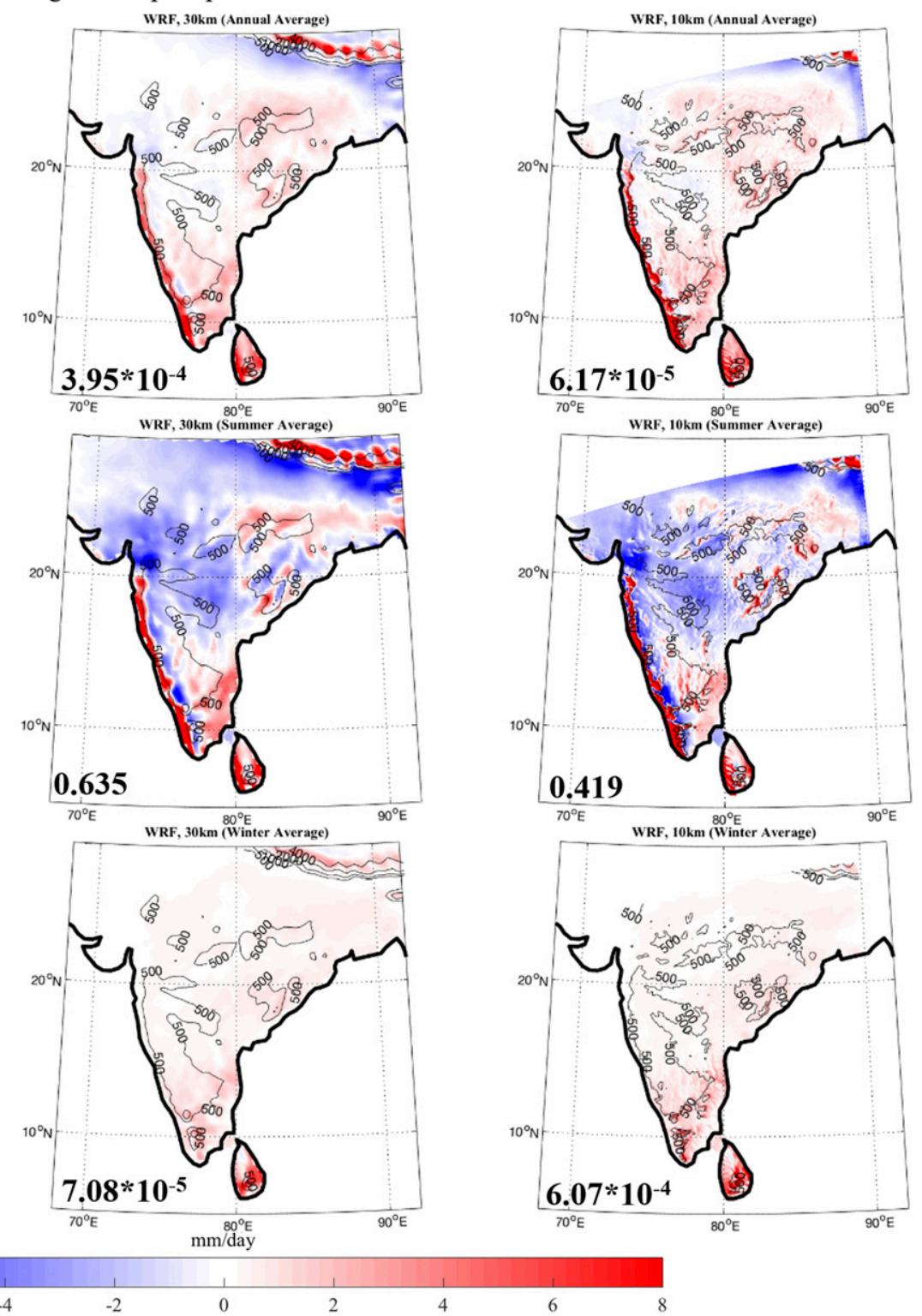

FIG. 6. (top) Annual-mean, (middle) summer, and (bottom) winter differences of total precipitation with respect to the CRU observational dataset, averaged over 15 years for (left) CESM, (center) outer WRF domain, and (right) inner WRF domain. The $p$ values of the $t$ test are shown in the bottom-left corners of each panel, and the topography contours $(\mathrm{m})$ are shown in the background.

to the observations derived from applying the downscaling methodology.

Temperature biases are generally more consistent between models than the precipitation biases, which is entirely expected, as surface temperature is a continuous field with higher spatial correlation than is precipitation. Besides, the temperature and precipitation biases of both CESM and WRF are more similar in winter than in summer. The winter large-scale weather systems that dominate the winter temperature fields are more consistent between CESM and WRF, while the parameterized land-air interactions on regional scales play a more important role in summer, contributing to the temperature differences between WRF and CESM. The same argument can be made regarding precipitation biases, where large-scale weather patterns are dominant in winter, while local convection is clearly strongest in summer.

Figure 7 shows the differences in the standard deviation (SD) of annually and seasonally averaged temperature in different models with respect to the CRU observations. In all seasons, CESM overestimates the temperature variability averaged over India. It has an overestimation of 


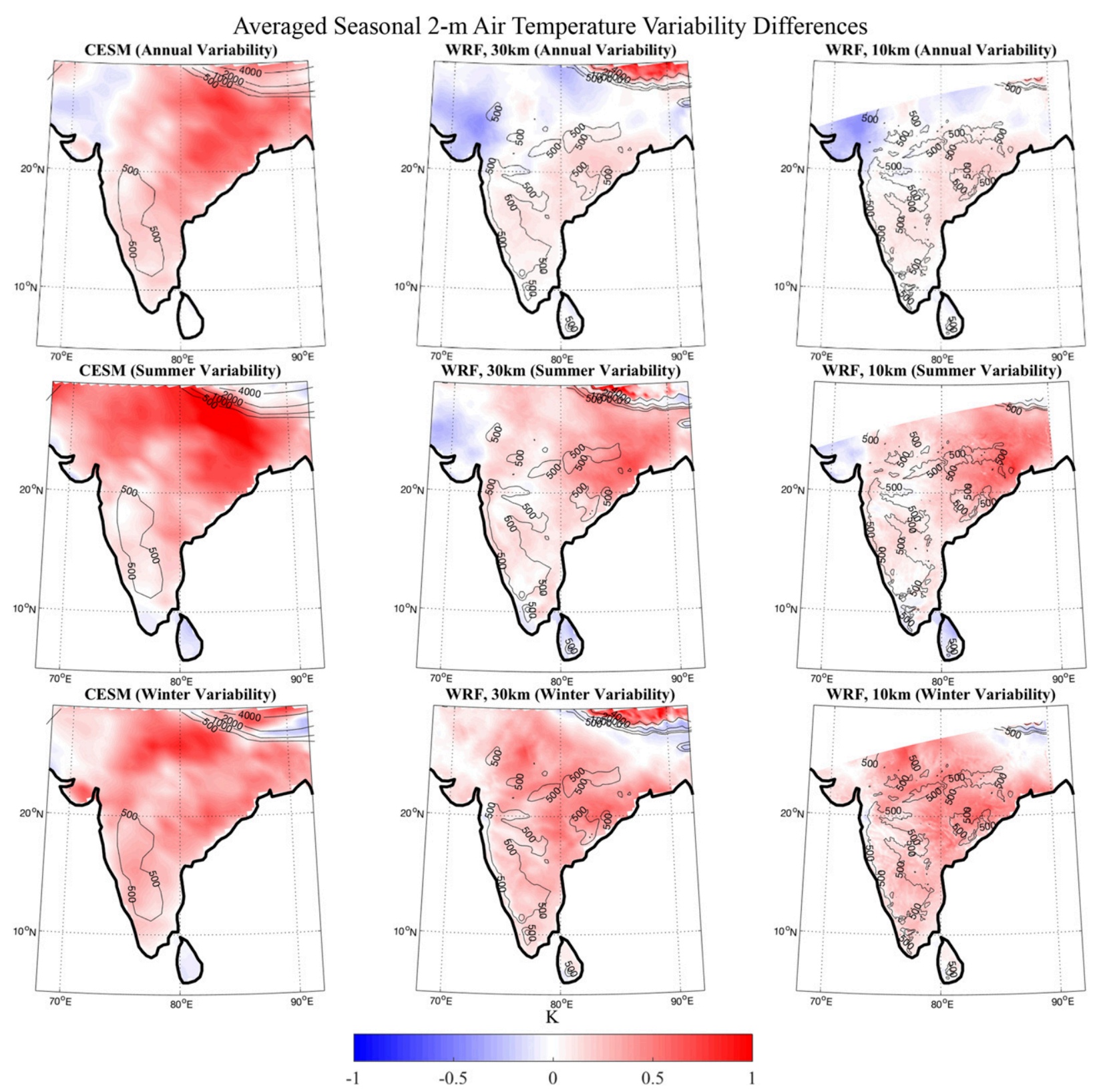

FIG. 7. Difference of SD of (top) annual, (middle) summer, and (bottom) winter temperature with respect to the CRU observational dataset in (left) CESM, (center) outer WRF domain, and (right) inner WRF domain.

$0.33^{\circ} \mathrm{C}$ in summer and an overestimation of $0.30^{\circ} \mathrm{C}$ in winter. WRF largely reduces these biases to an overestimation of $0.16^{\circ} \mathrm{C}$ in summer and an overestimation of $0.23^{\circ} \mathrm{C}$ in winter at both 30 - and $10-\mathrm{km}$ resolutions. The differences of the interannual SD of precipitation with respect to the observations are illustrated in Fig. 8. In summer, CESM underestimates the precipitation variability in the north and along the Western Ghats, but overestimates the variability in south India. The WRF simulations overcorrected the underestimation along the Western Ghats, resulting in a slight overestimation. In central India, a large overestimation of precipitation variability is characteristic of the WRF simulations although the simulated 15-yr-average summer rainfall in that region from WRF agrees well with the observations. The WRF simulations have also reduced the precipitation variability overestimation by the global model over south India.

\section{b. The average seasonal cycle of station clusters}

Figure 9 shows the climatological seasonal cycle of precipitation for station clusters 1 (central and south India), 2 (east coast of India), and 3 (Western Ghats). Observational 
Averaged Seasonal Precipitation Rate Variability Differences
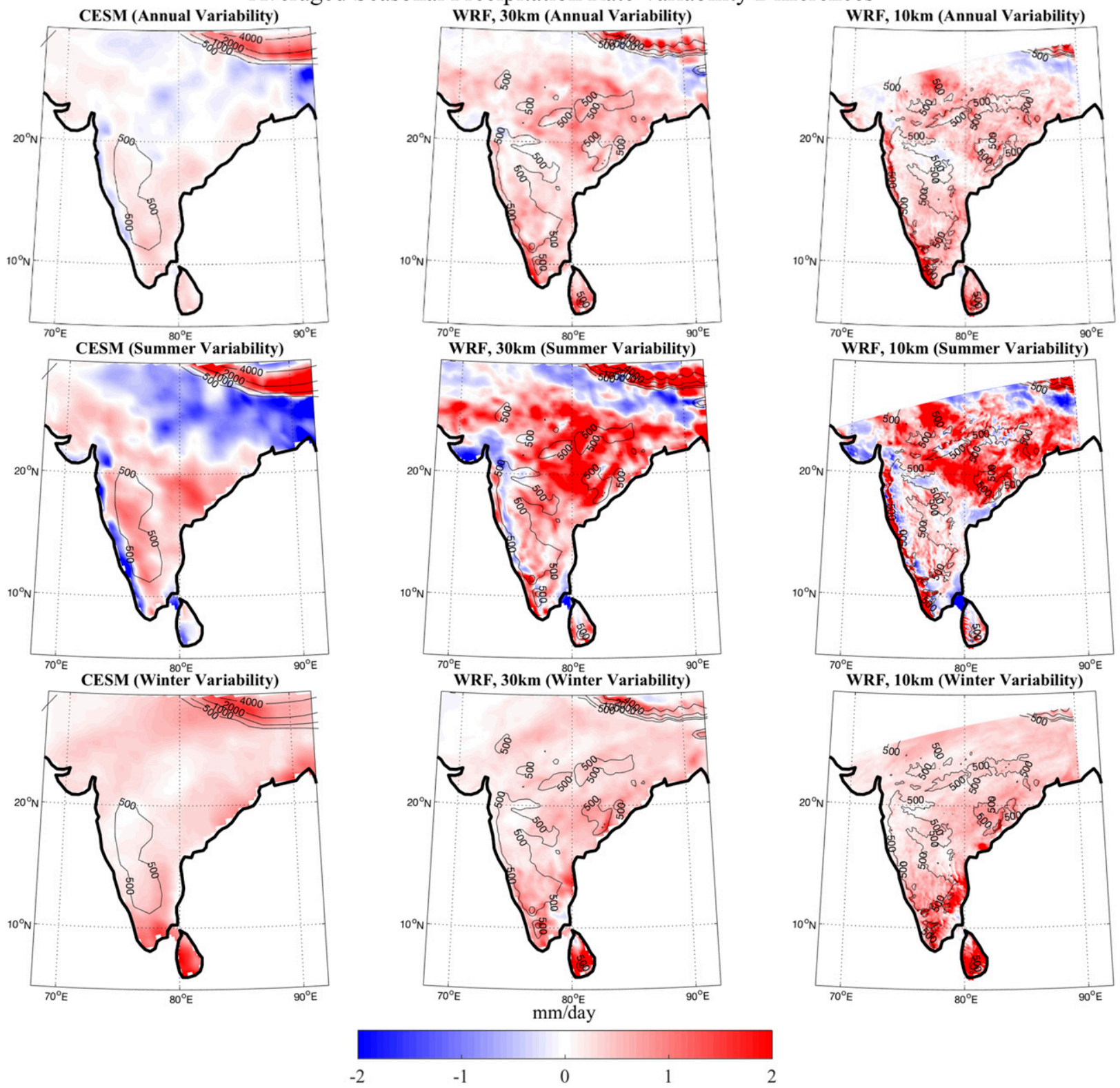

FIG. 8. As in Fig. 7, but for total precipitation.

data are shown as black lines with error bars, and WRF outer- and inner-domain data are shown as blue and red lines. The error bars and bands are based on the standard error of the mean (SEM), which is SEM $=s /(n)^{1 / 2}$, where $n$ is the number of samples (the number of years in this case) and $s$ is the sample standard deviation. The error bars and bands show the $95 \%$ confidence region, corresponding to approximately \pm 2 SEM. The standard error of the mean has been estimated for each station cluster as a whole.

Compared to station observations, summer precipitation in central and south India is significantly underestimated by WRF with $10-\mathrm{km}$ resolution, while it is overestimated for the Western Ghats. It is interesting to point out that in central and south India, the summer total precipitation rate from the WRF outer domain fits the observations better than the results from the WRF inner domain, probably because the $30-\mathrm{km}$-resolution results are characterized by a greater overestimation in the mountains in the northeast that compensates for the underestimation elsewhere in central and south India (Fig. 6). Furthermore, the peak in precipitation on the east coast occurs in fall and is likely due to high frontal 


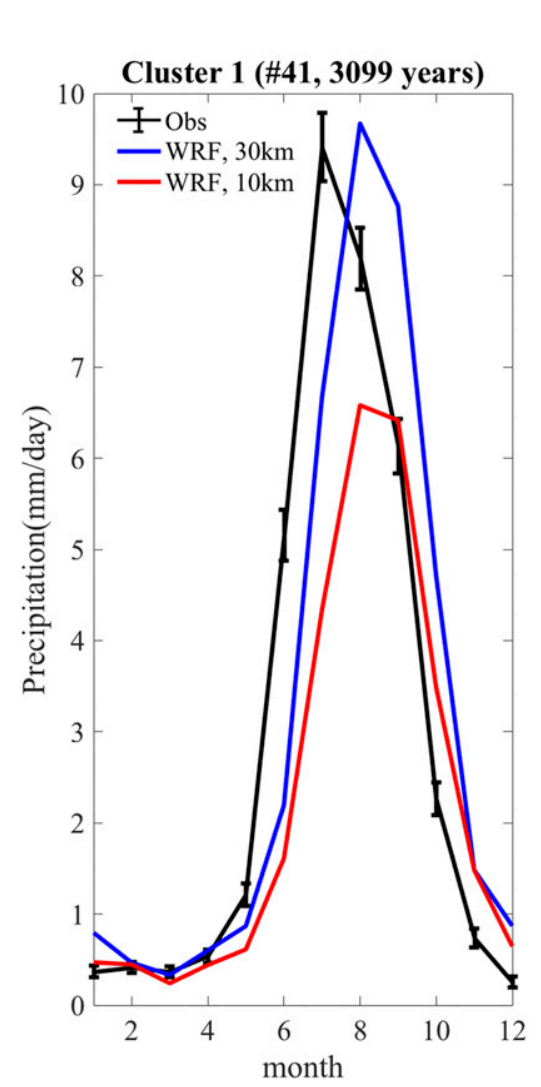

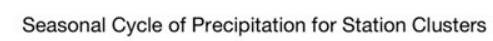

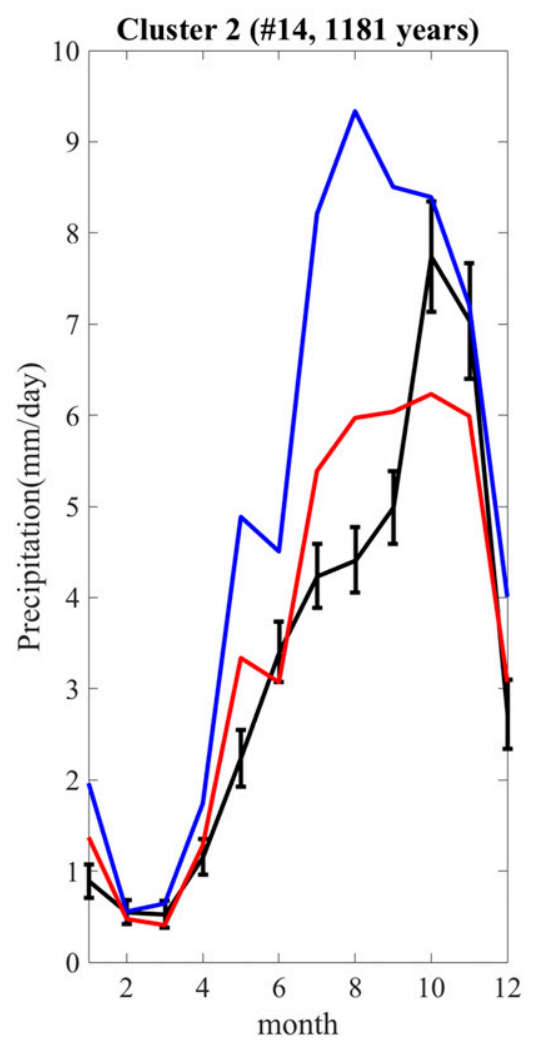

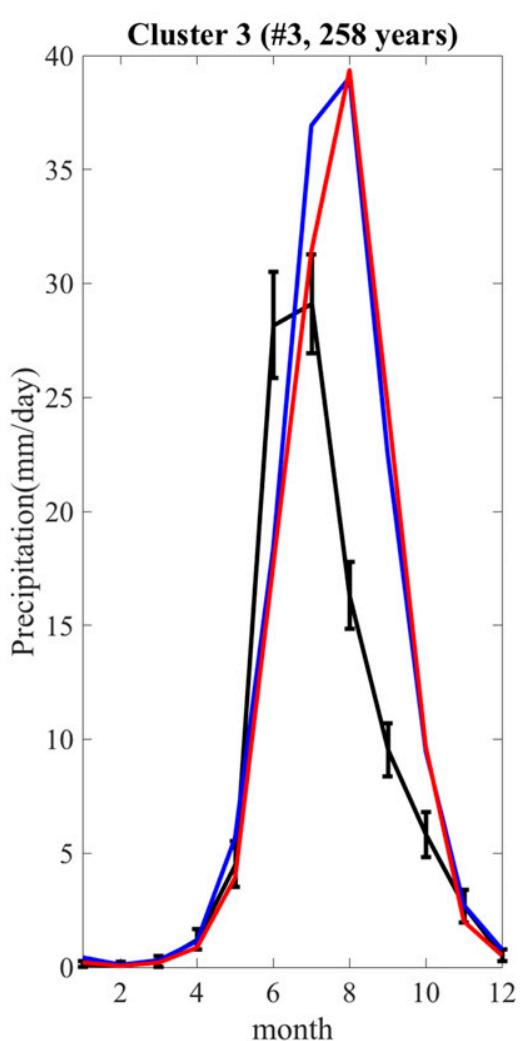

FIG. 9. Seasonal cycle of precipitation for station clusters from the GHCN observations (black), WRF outer domain (blue), and WRF inner domain (red). The error bars show the standard error of the climatological mean $\left[\sigma /(n)^{1 / 2}\right]$. The number of stations (\#) and the number of samples (years) for each cluster are indicated in the panel titles.

activity in this season. The total amount of summer precipitation is somewhat overestimated toward the coasts (clusters 2 and 3 ).

\section{c. Validation of the analysis of precipitation extremes}

The probability density functions (PDFs) of fitted GEV distributions, along with histograms of the observational data, for the validation period (1980-94) are shown in Fig. 10. PDFs are shown for the outer (blue; $30-\mathrm{km}$ resolution) and inner (red; $10-\mathrm{km}$ resolution) domains, as well as for the station observations (black). The numbers of stations and observational data points in the clusters are shown in the panel headers; the number of data points for the simulations is always the duration of the simulation (i.e., 15 years) multiplied by the number of stations. It is evident that in almost all clusters, the magnitude of daily precipitation extremes is approximately $40 \%$ weaker in the WRF ensemble than in observations (except in cluster 3 in the WRF inner domain, where the magnitude of model extremes is approximately $90 \%$ of the observed extremes). This is not surprising, because model values represent averages over individual grid cells while station observations represent point values. The reduction of the intensity of precipitation extremes due to temporal and spatial aggregation was investigated by Eggert et al. (2015), using high-resolution radar data over Germany and comparing extremes at different spatial scales. They found strong reduction for convective precipitation extremes (30\% stronger than for stratiform events), which may be partially responsible for the simulated reduction of precipitation extreme intensity in summer when convective precipitation dominates.

Bias-corrected (rescaled) model distributions are shown as dashed lines. In cluster 1, it is demonstrated that there is no apparent relationship between resolution and the quality of fit. This is plausible because summer precipitation is largely convective, which is parameterized in all models, so summer precipitation and extremes in relatively flat regions like central and south India depend more on the quality of the parameterization than the resolution of the model. The quality of fit along the east coast is worse than for cluster 1 , and in this coastal region there is an apparent dependence on resolution. The inner WRF 

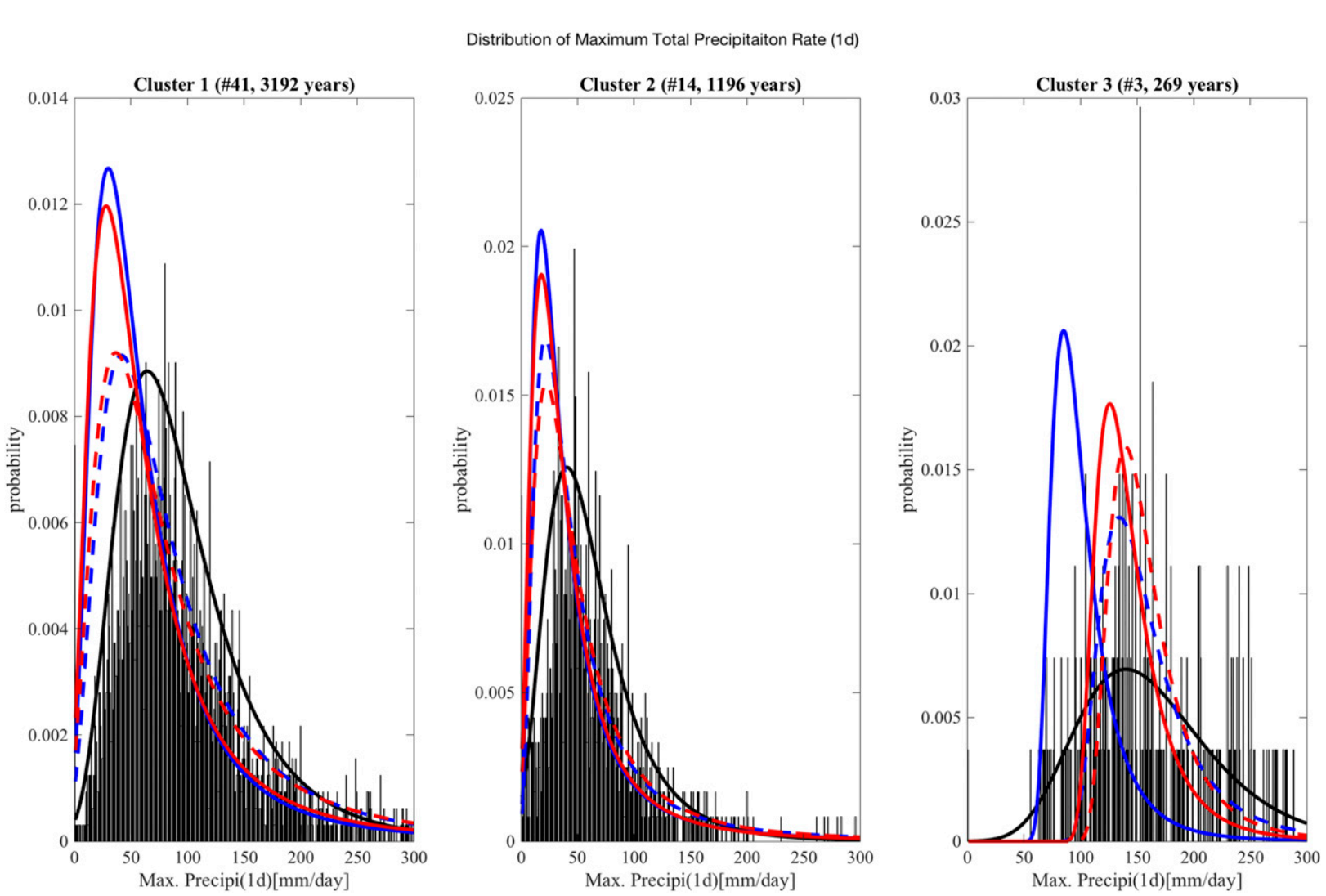

FIG. 10. Distribution of summer maxima of daily average precipitation with validation against observations in station clusters (left) 1 , (center) 2, and (right) 3: GHCN observations (black), WRF outer domain (blue), and WRF inner domain (red). The dashed lines are fits that were rescaled so that the mean and variance of the model distribution matches the distribution mean of the observed distribution. The number of stations (\#) and the number of samples (years) in summer for each cluster are indicated in the panel titles.

domain achieves a better fit than the outer domain, indicating once more-but in terms of extremes-the benefit of high resolution. In the Western Ghats, on the other hand, even the resolution of the outer domain $(30 \mathrm{~km})$ appears sufficient after bias correction to properly capture precipitation phenomenology.

Figure 11 characterizes the tail behavior of the distributions by showing daily precipitation intensities of rare (decadal return period) events. The model results have been bias corrected, so the historical model distributions have the same mean and standard deviation as the observations. The tail behavior of WRF outer domain simulations agrees better with observations in central and south India than the WRF inner domain though both show an overestimation (9\% for WRF outer domain and 30\% for WRF inner domain) in the intensity of 50-yr-return-period events. However, along the coasts (clusters 2 and 3 ) where the regions are characterized by complex topography, the tail behavior of WRF inner-domain simulations fits the observations better than the outer domain. WRF outer-domain data are characterized by a $44 \%$ overestimation ( $40 \%$ underestimation) in the intensity of 50-yr-return-period events before bias correction for cluster 2 (cluster 3), whereas the WRF inner domain has a $33 \%$ overestimation $(24 \%$ underestimation) in cluster 2 (cluster 3), which indicates the added value of higher resolution. However, it is interesting to note that after bias correction, the tail behavior of the WRF inner domain is almost identical to that of the outer domain in cluster 2, and the tail behavior of the WRF outer domain fits the observations even better than the inner domain in cluster 3 .

A stability test, performed by eliminating data from every other station, shows that the reduction in station number will reduce the quality of fit of model data to station data (see Fig. S1 in the supplementary material). This effect is more prominent in clusters that contain relatively fewer stations. This explains for the most part the large mismatch in cluster 3 , which has only three stations.

\section{Sensitivity to physics parameterizations}

To test the robustness of the results to variations in the schemes employed to represent unresolved processes, a physics ensemble based upon the use of a different land 

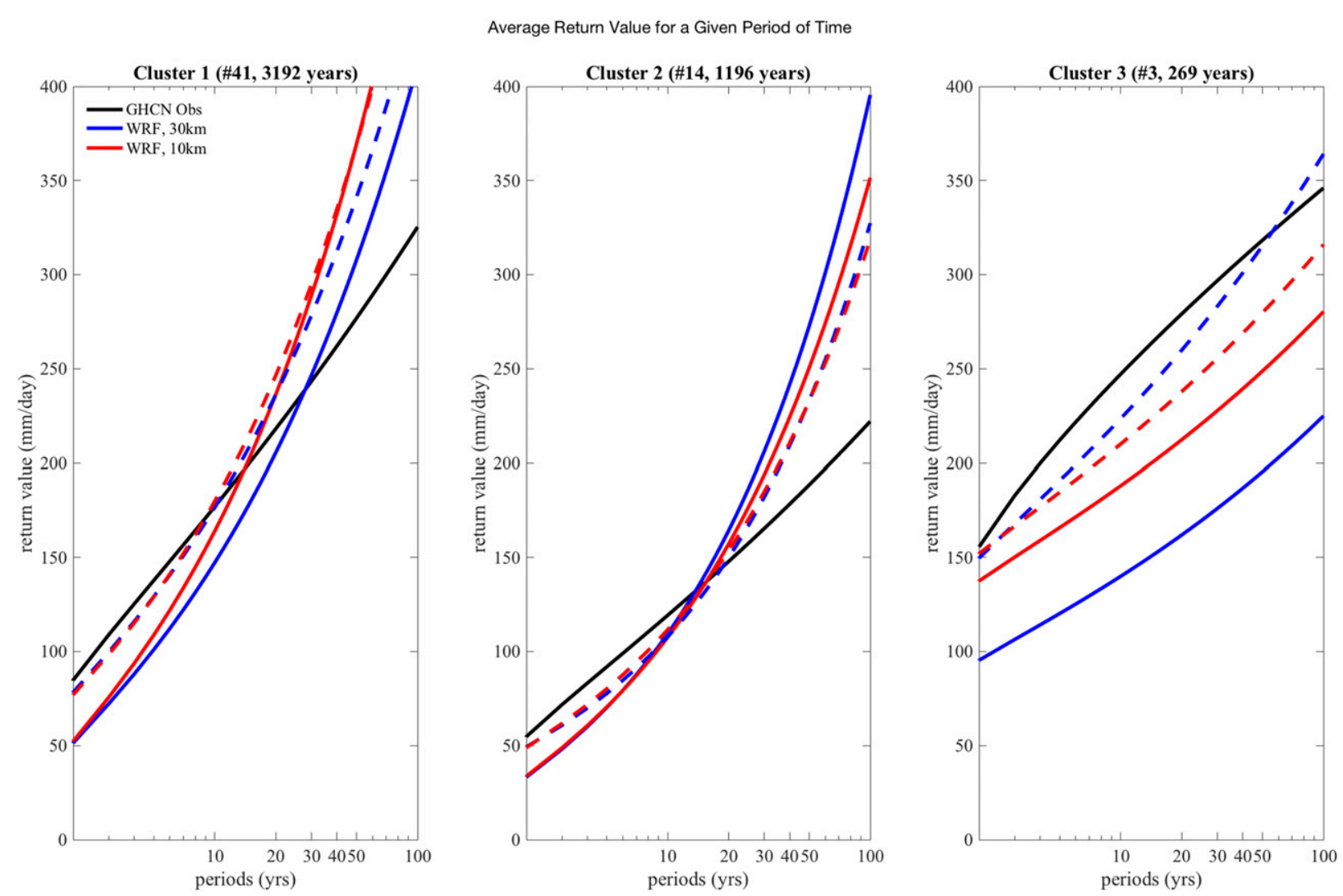

FIG. 11. Extreme quantiles of summer maxima of daily average precipitation for station clusters (left) 1, (center) 2, and (right) 3: GHCN observations (black), WRF outer domain (blue), and WRF inner domain (red). The dashed curves show results from the model distributions corrected to match the mean and standard deviation of the observed distribution; the solid curves are results without bias correction.

surface scheme and convective parameterizations was integrated and is discussed in this section.

\section{a. The role of land surface scheme}

The first column in Fig. 12 shows the 15-yr-average annual, summer, and winter temperature bias maps for the first WRF ensemble member, while the other four columns in Fig. 12 show the annual, summer, and winter temperature differences of the other three ensemble members and the ensemble mean with respect to the first ensemble member, with $p$ values from the $t$ test. Comparing the first and second ensemble members, whose only difference is the land surface scheme, the summer temperature bias is largely corrected by using the Noah multiphysics (NoahMP) land surface model. The average temperature biases in summer for the first and second ensemble members are $2.0^{\circ}$ and $0.4^{\circ} \mathrm{C}$, respectively. In winter, the Noah-MP land surface scheme reduces the cold bias in central India but also has a slightly larger cold bias in the south than the first ensemble member.

The summer precipitation rates of the first and second ensemble members are almost identical in most regions, suggesting that the land surface scheme does not play an important role in simulating monsoon precipitation (Fig. 13).

\section{$b$. The role of convective parameterization scheme}

To investigate the role of the parameterization scheme employed to represent cumulus convection, we compare results from the third and fourth ensemble members, which use the Grell-3 and the Tiedtke schemes, respectively, as opposed to the Kain-Fritsch scheme in the first ensemble member. Temperatures are still generally too cold in winter and too warm in summer compared to observations. However, it is evident in Fig. 12 that the third and fourth WRF ensemble members simulate summer temperatures much more accurately over the Indian peninsular region showing less warm bias compared to the KF convection scheme employed in the first ensemble member, despite the land surface model being the same (the Noah land surface model). Moreover, the fourth WRF ensemble member is also characterized by a smaller cold bias in winter $\left(-2.4^{\circ} \mathrm{C}\right)$ compared to that in the first ensemble 

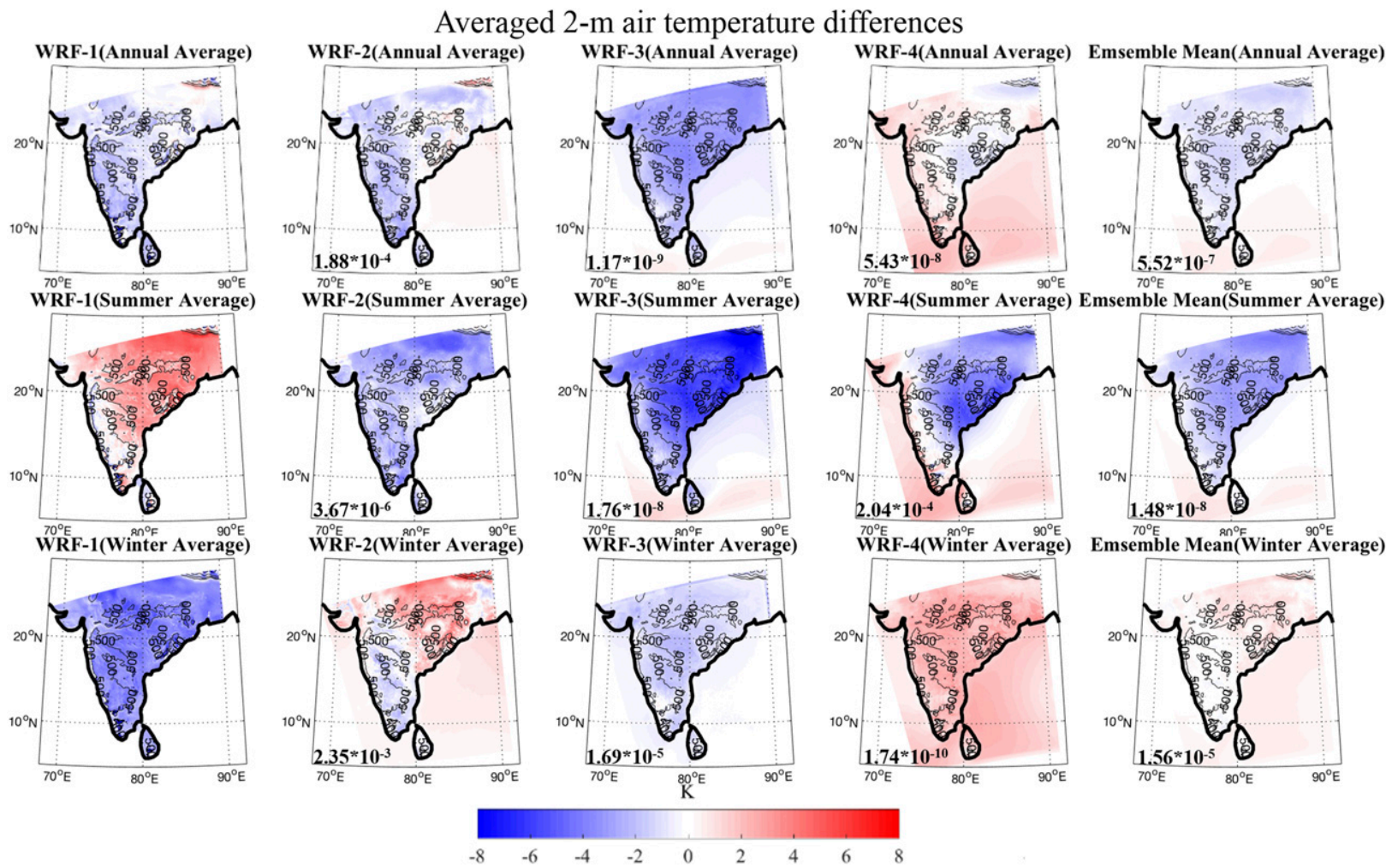

FIG. 12. (first column) (top) Annual-mean, (middle) summer, and (bottom) winter differences of 2-m air temperature with respect to the observational dataset, averaged over 15 years for the first WRF ensemble member (inner domain). (second column)-(fifth column) (top) Annual-mean, (middle) summer, and (bottom) winter differences of 2-m air temperature with respect to the first WRF ensemble member, averaged over 15 years for the second-fourth WRF ensemble members and the ensemble mean (inner domain), with the $p$ values of the $t$ test in the bottom-left corners of each panel. The topography contours (m) are also shown in the background.

member $\left(-3.1^{\circ} \mathrm{C}\right)$. This reduction in temperature bias is very likely due to a reduction of solar (shortwave) radiation being received in summer in the third and fourth WRF ensemble members and more solar radiation being received in winter at the ground surface in the fourth WRF ensemble member (see Fig. S2 in the supplementary material), which most probably results from a difference in cloud cover (i.e., more cloud cover in the third and fourth WRF ensemble members in summer and less cloud cover in the fourth WRF ensemble member in winter).

Summer precipitation is mainly convective and has large spatial variability, implying that it is directly influenced by model resolution and the cumulus parameterization scheme. The summer precipitation biases from the third and fourth WRF configurations, which employ different moist physics parameterizations, are shown in Fig. 13 for comparison. The third WRF ensemble member with the Grell-3 convection scheme reasonably simulates the spatial distribution of summer monsoon precipitation over India. In terms of intensity, however, the Grell-3 scheme overestimates the precipitation over the rain barrier in the
Western Ghats. This is probably due to the strong upward motion, which triggers moist convection in the Grell-3 scheme. On the contrary, the Tiedtke scheme in the fourth ensemble member has a general tendency to result in a drier precipitation bias, whereas it slightly overestimates the precipitation in south India, which agrees with the findings of P. V. S. Raju et al. (2015) and Ali et al. (2015) based on the simulation of South Asian summer monsoon using the RegCM model at 45- and 20-km horizontal resolutions, respectively.

Results from the ensemble mean are also shown in Figs. 12 and 13. Since temperature biases are generally more consistent among different ensemble members than the precipitation biases (i.e., all ensemble members have an overall cold bias in winter and a warm bias in summer), the ensemble mean is hardly better than the individual members in terms of temperature simulation (Fig. 12). However, the ensemble mean has a smaller overall summer precipitation bias than the individual members because these members have biases of opposite signs in some regions (e.g., in the Satpura Range). Besides, the summer precipitation differences between the ensemble mean and 

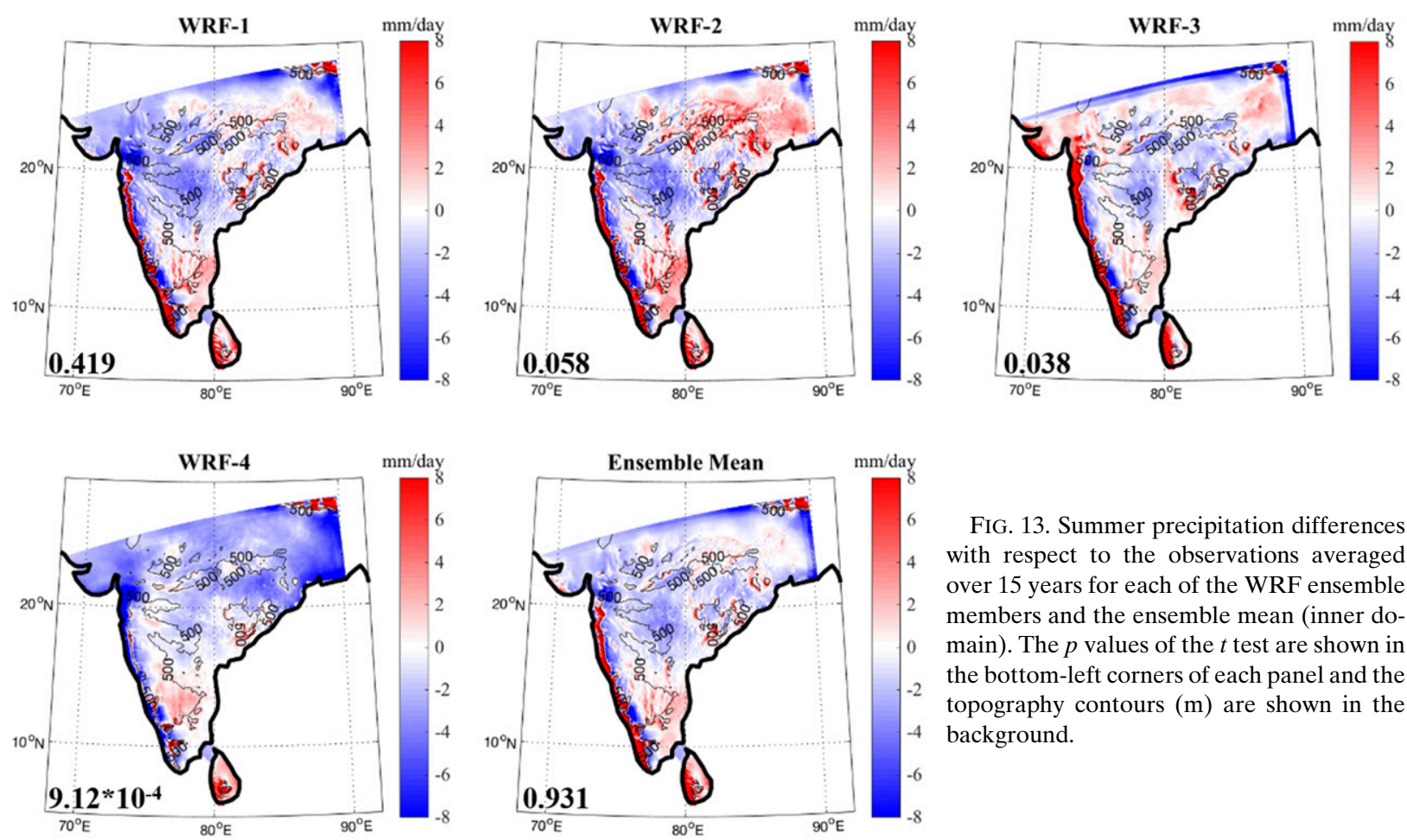

FIG. 13. Summer precipitation differences with respect to the observations averaged over 15 years for each of the WRF ensemble members and the ensemble mean (inner domain). The $p$ values of the $t$ test are shown in the bottom-left corners of each panel and the topography contours $(\mathrm{m})$ are shown in the background.

observational dataset are not statistically significant, and the $p$ value of the $t$ test for the ensemble mean is larger than those for all the individual members. As a result, the ensemble mean can be considered to best reproduce the Indian summer precipitation field in general despite a slightly larger moist bias in the southeast corner than the fourth ensemble member (Fig. 13).

In the simulation of a thermally direct circulation such as the Indian monsoon, the extent to which the observed thermodynamic structure of the system is reproduced is also worthy of investigation. In a convective quasi-equilibrium $(\mathrm{QE})$ framework (Nie et al. 2010), which has been employed previously in theoretical studies of monsoon dynamics (Chou et al. 2001; Neelin 2007), cumulus convection vertically couples temperature within the convecting layer to the moist static energy of air below cloud base $h_{b}$ and the zonal wind shear can be approximated as (Prive and Plumb 2007a)

$$
\frac{\partial u}{\partial p} \cong \frac{1}{f}\left(\frac{\partial T}{\partial p}\right)_{s^{*}} \frac{1}{T_{b}} \frac{\partial h_{b}}{\partial y}
$$

where $f$ is the Coriolis parameter, $s^{*}$ is the saturation moist entropy, and $T_{b}$ is the mean subcloud temperature. The subtropical meridional gradient of subcloud moist static energy is therefore positively correlated with the strength of the Indian monsoon and the location of the $h_{b}$ maximum marks the zero-wind-shear line and thus the poleward edge of the ascent branch of the thermally direct monsoon circulation (e.g., Emanuel 1995; Prive and Plumb 2007a). Therefore, in order to assess how well climate models reproduce the observed thermodynamic structure of the monsoon circulation, surface air moist static energy, which can be calculated with available climate model output as $h_{b}=C_{p} T+g z+L_{v} q$, may be employed as the measure of subcloud moist static energy. Here, the quantities correspond to the heat capacity of the atmosphere $C_{p}$, the absolute air temperature $T$, the gravitational acceleration $g$, the height above the surface $z$, the latent heat of vaporization $L_{v}$, and water vapor specific humidity $q$. Figure 14 shows the zonal-mean surface air moist static energy over India in July for CESM (black), ERA-Int (blue), each of the WRF ensemble members and the ensemble mean. Results for most of the WRF ensemble members closely resemble that of the CESM with a general overestimation when compared to ERA-Int, while the third ensemble member based upon use of the Grell-3 convection scheme is characterized by a zonal average more consistent with the ERA-Int. Although the Grell-3 convection scheme reasonably simulates the spatial distribution of summer 


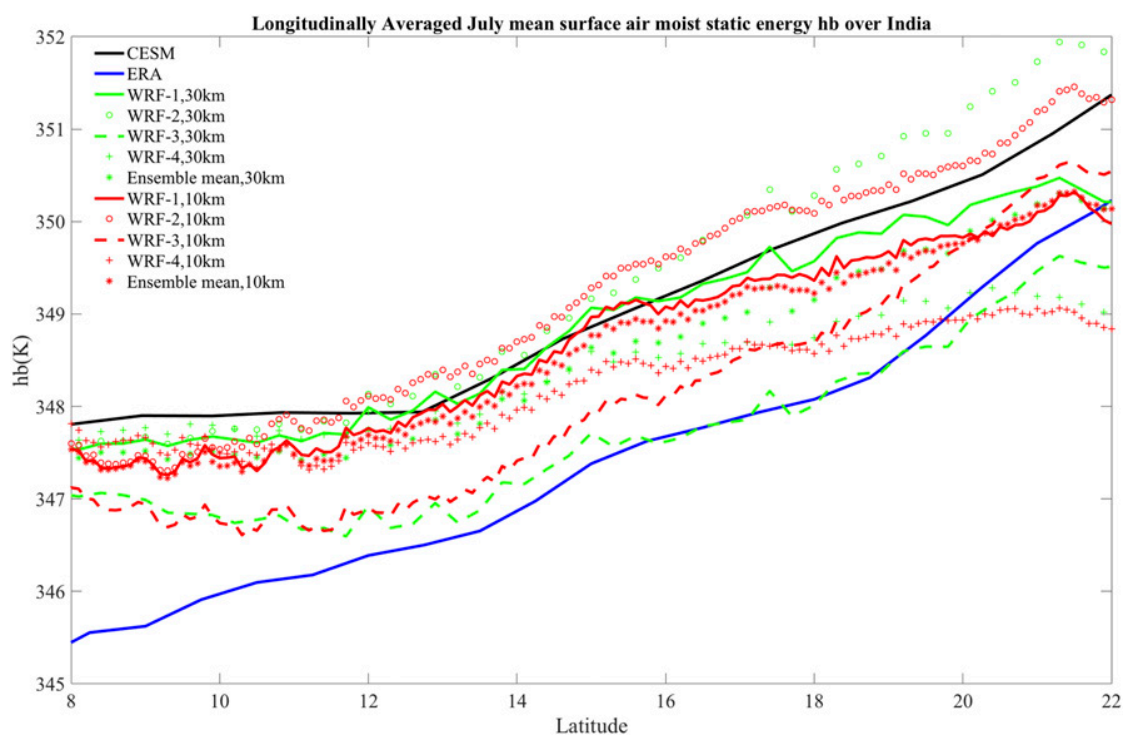

FIG. 14. Zonal-mean surface air moist static energy $h_{b}$ over India in July for CESM (black), ERA-Int (blue), and each of the WRF ensemble members and the ensemble mean: outer domain (green) and inner domain (red).

monsoon precipitation over India, the third ensemble member is characterized by a significant overestimation of summer precipitation in the region west of the Western Ghats. Therefore, surface air moist static energy, which is considered to be a useful diagnostic of the thermodynamic structure of the monsoon circulation, appears to fail as a measure of how well models reproduce the monsoon precipitation field in regions with complex topography like the Western Ghats. This result is perhaps not unexpected given the simplicity of the assumptions on which the moist static energy diagnostic is based. The average meridional gradients of surface air moist static energy over India for different models and resolutions are listed in Table 2. Meridional gradients marked in boldface are those that are not significantly different from the meridional gradient derived from the ERA-Int ( $p$ values $>0.05$ for the Student's $t$ test). The meridional gradient from the ERA-Int is somewhat larger than those of all of the other models and the gradient calculated for the fourth WRF ensemble member has the largest negative bias, which could explain the significant dry bias of this model since the meridional gradient of subcloud moist static energy is positively correlated with the strength of the Indian monsoon (Prive and Plumb 2007a). However, although the meridional gradient of moist static energy from the second WRF ensemble member is closest to that derived from the ERA-Int data and their differences are not statistically significant, the second ensemble member does not produce the best precipitation field when compared to the observations (e.g., it shows the largest summer wet bias in the northeast of India among the four physics ensemble members for which results are shown in Fig. 13), which implies that in addition to moist static entropy, other factors like orography play an important role in Indian monsoon precipitation.

\section{Summary and conclusions}

We have presented dynamically downscaled highresolution climate simulations for India, with an analysis of precipitation extremes and of the sensitivity of model results to the physics parameterization schemes employed to represent subgrid-scale processes. Compared to CESM, WRF significantly improves the representation of orographic precipitation and the variation across the seasonal cycle. Nevertheless, precipitation in the rain shadow of the Western Ghats is slightly underestimated, while it is overestimated in CESM. CESM and all WRF configurations also suffer from a cold bias in winter.

An approach based upon the pooling of data from stations with a similar mean climatology was employed for the analysis of precipitation extremes. Validation against station observations has shown that the tail distribution of precipitation extremes from the 30-km-resolution version of the WRF Model fits the observations better in central and south India than does the 10-km-resolution WRF simulations. However, in the Western Ghats and on the east coast of India where the topography is relatively more complex, results from the WRF inner domain are superior to those from the coarse-resolution outer domain when considering 50-yr-return-period events. 
TABLE 2. The average meridional gradient $\left(\mathrm{K} \mathrm{degree}^{-1}\right)$ of surface air moist static energy $h_{b}$ over India for different models and resolutions. Meridional gradients marked in boldface are those that are not significantly different from the meridional gradient derived from the ERA-Int ( $p$ values $>0.05$ for the Student's $t$ test).

\begin{tabular}{cccccc}
\hline \hline CESM & ERA-Int & $\begin{array}{c}\text { First WRF } \\
\text { ensemble member } \\
(30 \mathrm{~km})\end{array}$ & $\begin{array}{c}\text { First WRF } \\
\text { ensemble member } \\
(10 \mathrm{~km})\end{array}$ & $\begin{array}{c}\text { Second WRF } \\
\text { ensemble member } \\
(30 \mathrm{~km})\end{array}$ & $\begin{array}{c}\text { Second WRF } \\
\text { ensemble member } \\
(10 \mathrm{~km})\end{array}$ \\
\hline 0.31 & 0.37 & 0.24 & 0.23 & $\mathbf{0 . 3 5}$ & $\mathbf{0 . 3 4}$ \\
$\begin{array}{c}\text { Third WRF ensemble } \\
\text { member }(30 \mathrm{~km})\end{array}$ & $\begin{array}{c}\text { Third WRF ensemble } \\
\text { member }(10 \mathrm{~km})\end{array}$ & $\begin{array}{c}\text { Fourth WRF ensemble } \\
\text { member }(30 \mathrm{~km})\end{array}$ & $\begin{array}{c}\text { Fourth WRF ensemble } \\
\text { member }(10 \mathrm{~km})\end{array}$ & $\begin{array}{c}\text { Ensemble } \\
\text { mean }(30 \mathrm{~km})\end{array}$ & $\begin{array}{c}\text { Ensemble } \\
\text { mean }(10 \mathrm{~km})\end{array}$ \\
\hline 0.26 & $\mathbf{0 . 3 3}$ & 0.11 & 0.14 & 0.25 & 0.26 \\
\hline
\end{tabular}

A small physics ensemble was employed to investigate the sensitivity to different physics parameterization schemes. These ensemble members have different strengths and weaknesses insofar as the temperature and precipitation simulations are concerned. However, as is often the case with ensembles based upon regional climate model simulations, no particular simulation can be thought to best represent both precipitation and temperature. The Noah-MP land surface scheme in the second ensemble member produces smaller summer warm bias compared to that of the first ensemble member, which uses the simple Noah land surface scheme. Compared with the KF cumulus scheme in the first ensemble member, the Grell-3 scheme produces higher moist bias at the first rain barrier, whereas the Tiedtke scheme is characterized by weaker precipitation over the entire Indian subcontinent. Furthermore, the Grell-3 and Tiedtke cumulus schemes can also reduce the summer warm bias through a change in solar radiation received at the ground surface. Moreover, the Tiedtke cumulus scheme is characterized by the smallest cold bias in winter among the four physics ensemble members analyzed. The ensemble mean is hardly better than any one of the individual members in terms of the temperature simulation, but it has a smaller overall bias than any one of the individual members in terms of summer precipitation.

The scale interactions over the South Asian region are extremely complex and are further complicated by the influence of intricate orography over the Himalayas and land-ocean-atmospheric interactions. Furthermore, global warming seems to be slowly changing the monsoon circulation in such a way as to make the climate of the Indian subcontinent more unpredictable. In the next phase of this study, we will perform climate change projections for the mid- and late twenty-first century and compare those results with the historical simulations discussed herein, so as to contribute to the understanding of the impact of climate change on the Indian monsoon. Details of the future projected changes in precipitation for India based on high-resolution regional climate simulations will be further discussed in detail elsewhere. Further insight will be provided by employing an initial condition ensemble of global integrations to drive the downscaling pipeline so as to provide a means of estimating the nature of the impact of internal variability, especially that related to ENSO, upon our model-based inferences of monsoon futures.

Acknowledgments. The simulations presented in this paper were performed on the SciNet High Performance Computing facility at the University of Toronto, which is a component of the Compute Canada HPC platform. The authors thank Dr. Andre Erler for assistance with the initial setup of the modeling chain and the SciNet team for assistance during the setup and operation of WRF. The research of WRP at the University of Toronto is supported by NSERC Discovery Grant 9627.

\section{REFERENCES}

Ali, S., D. Li, F. Congbin, and Y. Yang, 2015: Performance of convective parameterization schemes in Asia using RegCM: Simulations in three typical regions for the period 1998-2002. Adv. Atmos. Sci., 32, 715-730, https://doi.org/10.1007/s00376014-4158-4.

An, Z., J. Kutzbach, W. Prell, and S. Porter, 2001: Evolution of Asian monsoons and phased uplift of the Himalaya-Tibetan plateau since Late Miocene times. Nature, 411, 62-66, https:// doi.org/10.1038/35075035.

Bolin, B., 1950: On the influence of the earth's orography on the westerlies. Tellus, 2, 184-195, https://doi.org/10.3402/tellusa v2i3.8547.

Charney, J. G., and A. Eliassen, 1949: A numerical method for predicting in the perturbation of the middle latitude westerlies. Tellus, 1, 38-54, https://doi.org/10.3402/tellusa. v1i2.8500.

Chou, C., J. D. Neelin, and H. Su, 2001: Ocean-atmosphere-land feedbacks in an idealized monsoon. Quart. J. Roy. Meteor. Soc., 127, 1869-1891, https://doi.org/10.1002/qj.49712757602.

Coles, S., 2001: An Introduction to Statistical Modeling of Extreme Values. Springer Series in Statistics, Vol. 208, Springer, 209 pp., https://doi.org/10.1007/978-1-4471-3675-0.

Cook, E. R., K. J. Anchukaitis, B. M. Buckley, R. D. D'Arrigo, G. C. Jacoby, and W. E. Wright, 2010: Asian monsoon failure and megadrought during the last millennium. Science, $\mathbf{3 2 8}$, 486-489, https://doi.org/10.1126/science.1185188. 
Davies, H., and R. E. Turner, 1977: Updating prediction models by dynamical relaxation: An examination of the technique. Quart. J. Roy. Meteor. Soc., 103, 225-245, https://doi.org/ 10.1002/qj.49710343602.

Dee, D. P., and Coauthors, 2011: The ERA-Interim reanalysis: Configuration and performance of the data assimilation system. Quart. J. Roy. Meteor. Soc., 137, 553-597, https://doi.org/ 10.1002/qj.828.

Deser, C., A. Phillips, V. Bourdette, and H. Teng, 2012: Uncertainty in climate change projections: The role of internal variability. Climate Dyn., 38, 527-546, https://doi.org/10.1007/ s00382-010-0977-x.

d'Orgeville, M., W. R. Peltier, A. R. Erler, and J. Gula, 2014: Climate change impacts on Great Lakes Basin precipitation extremes. J. Geophys. Res. Atmos., 119, 10 799-10 812, https:// doi.org/10.1002/2014JD021855.

Eggert, B., P. Berg, J. Haerter, D. Jacob, and C. Moseley, 2015: Temporal and spatial scaling impacts on extreme precipitation. Atmos. Chem. Phys., 15, 5957-5971, https://doi.org/ 10.5194/acp-15-5957-2015.

Emanuel, K. A., 1995: On thermally direct circulations in moist atmospheres. J. Atmos. Sci., 52, 1529-1536, https://doi.org/ 10.1175/1520-0469(1995)052<1529:OTDCIM>2.0.CO;2.

Erler, A. R., and W. R. Peltier, 2016: Projected changes in precipitation extremes for western Canada based on high-resolution regional climate simulations. J. Climate, 29, 8841-8863, https:// doi.org/10.1175/JCLI-D-15-0530.1.

_ - — and M. d'Orgeville, 2015: Dynamically downscaled highresolution hydroclimate projections for western Canada. J. Climate, 28, 423-450, https://doi.org/10.1175/JCLI-D-14-00174.1.

Fita, L., J. Fernández, and M. Garcia-Dez, 2010: CLWRF: WRF modifications for regional climate simulation under future scenarios. 11th WRF Users' Workshop, Boulder, CO, NCAR, P.26, http://www2. mmm.ucar.edu/wrf/users/workshops/WS2010/abstracts/P-26.pdf.

Flato, G., and Coauthors, 2013: Evaluation of climate models. Climate Change 2013: The Physical Science Basis, T. F. Stocker et al., Eds., Cambridge University Press, 741-866.

Flohn, H., 1968: Contributions to a meteorology of the Tibetan Highlands. Colorado State University Tech. Rep. 130, 120 pp.

Gent, P. R., and Coauthors, 2011: The Community Climate System Model version 4. J. Climate, 24, 4973-4991, https://doi.org/ 10.1175/2011JCLI4083.1.

Goswami, B. N., V. Venugopal, D. Sengupta, M. S. Madhusoodanan, and P. K. Xavier, 2006: Increasing trend of extreme rain events over India in a warming environment. Science, 314, 1442-1445, https://doi.org/10.1126/science.1132027.

Grell, G. A., and D. Dévényi, 2002: A generalized approach to parameterizing convection combining ensemble and data assimilation techniques. Geophys. Res. Lett., 29, 1693, https:// doi.org/10.1029/2002GL015311.

Gula, J., and W. R. Peltier, 2012: Dynamical downscaling over the Great Lakes Basin of North America using the WRF regional climate model: The impact of the Great Lakes system on regional greenhouse warming. J. Climate, 25, 7723-7742, https:// doi.org/10.1175/JCLI-D-11-00388.1.

Guo, D., and H. Wang, 2016: Comparison of a very-fine-resolution GCM with RCM dynamical downscaling in simulating climate in China. Adv. Atmos. Sci., 33, 559, https://doi.org/10.1007/ s00376-015-5147-y.

Harris, I., P. D. Jones, T. J. Osborn, and D. H. Lister, 2014: Updated high-resolution grids of monthly climatic observations-The CRU TS3.10 dataset. Int. J. Climatol., 34, 623-642, https:// doi.org/10.1002/joc.3711.
Hartigan, J. A., and M. A. Wong, 1979: Algorithm AS 136: A K-means clustering algorithm. J. Roy. Stat. Soc., 28C, 100-108.

Hawkins, E., T. M. Osborne, C. K. Ho, and A. J. Challinor, 2013: Calibration and bias correction of climate projections for crop modelling: An idealized case study over Europe. Agric. For. Meteor., 170, 19-31, https://doi.org/10.1016/j.agrformet.2012.04.007.

Hong, S.-Y., and J.-O. J. Lim, 2006: The WRF single-moment 6-class microphysics scheme (WSM6). J. Korean Meteor. Soc., 42, 129-151.

Hosking, J. R. M., and J. R. Wallis, 1997: Regional Frequency Analysis: An Approach Based on L-Moments. Cambridge University Press, $240 \mathrm{pp}$.

Hostetler, S. W., J. R. Alder, and A. M. Allan, 2011: Dynamically downscaled climate simulations over North America: Methods, evaluation and supporting documentation for users. U.S. Geological Survey Open-File Rep. 2011-1238, 64 pp.

Iacono, M. J., J. S. Delamere, E. J. Mlawer, M. W. Shephard, S. A. Clough, and W. D. Collins, 2008: Radiative forcing by longlived greenhouse gases: Calculations with the AER radiative transfer models. J. Geophys. Res., 113, D13103, https://doi.org/ 10.1029/2008JD009944.

Ji, Z., and S. Kang, 2013: Double-nested dynamical downscaling experiments over the Tibetan Plateau and their projection of climate change under two RCP scenarios. J. Atmos. Sci., 70, 1278-1290, https://doi.org/10.1175/JAS-D-12-0155.1.

Kain, J. S., 2004: The Kain-Fritsch convective parameterization: An update. J. Appl. Meteor., 43, 170-181, https://doi.org/ 10.1175/1520-0450(2004)043<0170:TKCPAU>2.0.CO;2.

Kripalani, R. H., A. Kulkarni, S. S. Sabade, and M. L. Khandekar, 2003: Indian monsoon variability in a global warming scenario. Nat. Hazards, 29, 189-206, https://doi.org/10.1023/ A:1023695326825.

Kummerow, C., J. Simpson, O. Thiele, W. Barnes, A. T. C. Chang, E. Stocker, R. F. Adler, and A. Hou, 2000: The status of the tropical rainfall measuring mission (TRMM) after two years in orbit. J. Appl. Meteor., 39, 1965-1982, https://doi.org/10.1175/ 1520-0450(2001)040<1965:TSOTTR > 2.0.CO;2.

Loo, Y. Y., L. Billa, and A. Singh, 2014: Effect of climate change on seasonal monsoon in Asia and its impact on the variability of monsoon rainfall in Southeast Asia. Geosci. Front., 6, 817-823, https://doi.org/10.1016/j.gsf.2014.02.009.

Menne, M. J., I. Durre, R. S. Vose, B. E. Gleason, and T. G. Houston, 2012: An overview of the Global Historical Climatology Network-Daily database. J. Atmos. Oceanic Technol., 29, 897-910, https://doi.org/10.1175/JTECH-D-11-00103.1.

Miguez-Macho, G., G. L. Stenchikov, and A. Robock, 2004: Spectral nudging to eliminate the effects of domain position and geometry in regional climate model simulations. J. Geophys. Res., 109, D13104, https://doi.org/10.1029/ 2003JD004495.

Mukhopadhyay, P., S. Taraphdar, B. N. Goswami, and K. Krishnakumar, 2010: Indian summer monsoon precipitation climatology in a high-resolution regional climate model: Impact of cumulus parameterization schemes on systematic biases. Wea. Forecasting, 25, 369-387, https://doi.org/10.1175/2009WAF2222320.1.

Nakanishi, M., and H. Niino, 2009: Development of an improved turbulence closure model for the atmospheric boundary layer. J. Meteor. Soc. Japan, 87, 895-912, https://doi.org/10.2151/ jmsj.87.895.

Neelin, J., 2007: Moist dynamics of tropical convection zones in monsoons, teleconnections, and global warming. The Global Circulation of the Atmosphere, T. Schneider and A. H. Sobel, Eds., Princeton University Press, 267-301. 
Nie, J., W. Boos, and Z. Kuang, 2010: Observational evaluation of a convective quasi-equilibrium view of monsoons. J. Climate, $\mathbf{2 3}$, 4416-4428, https://doi.org/10.1175/2010JCLI3505.1.

Niu, G.-Y., and Coauthors, 2011: The community Noah land surface model with multiparameterization options (Noah-MP): 1. Model description and evaluation with local-scale measurements. J. Geophys. Res., 116, D12109, https://doi.org/10.1029/2010JD015139.

Pielke, R. A., 2001: Influence of the spatial distribution of vegetation and soils on the prediction of cumulus convective rainfall. Rev. Geophys., 39, 151-177, https://doi.org/10.1029/1999RG000072.

Prive, N. C., and R. A. Plumb, 2007a: Monsoon dynamics with interactive forcing. Part I: Axisymmetric studies. J. Atmos. Sci., 64, 1417-1430, https://doi.org/10.1175/JAS3916.1.

, and $-2007 \mathrm{~b}$ : Monsoon dynamics with interactive forcing. Part II: Impact of eddies and asymmetric geometries. J. Atmos. Sci., 64, 1431-1442, https://doi.org/10.1175/JAS3917.1.

Raju, A., A. Parekh, J. S. Chowdary, and C. Gnanaseelan, 2015: Assessment of the Indian summer monsoon in the WRF regional climate model. Climate Dyn., 44, 3077-3100, https://doi.org/ 10.1007/s00382-014-2295-1.

Raju, P. V. S., R. Bhatla, M. Almazroui, and M. Assiri, 2015: Performance of convection schemes on the simulation of summer monsoon features over the South Asia CORDEX domain using RegCM-4.3. Int. J. Climatol., 35, 4695-4706, https://doi.org/10.1002/joc.4317.

Roxy, M. K., K. Ritika, P. Terray, and S. Masson, 2014: The curious case of Indian Ocean warming. J. Climate, 27, 8501-8509, https://doi.org/10.1175/JCLI-D-14-00471.1.

,,,--- R. Murtugudde, K. Ashok, and B. N. Goswami, 2015: Drying of Indian subcontinent by rapid Indian Ocean warming and a weakening land-sea thermal gradient. Nat. Commun., 6, 7423, https://doi.org/10.1038/ncomms 8423 .

, S. Ghosh, A. Pathak, R. Athulya, M. Mujumdar, R. Murtugudde, P. Terray, and M. Rajeevan, 2017: A threefold rise in widespread extreme rain events over central India. Nat. Commun., 8, 708, https://doi.org/10.1038/s41467-017-00744-9.

Rupa Kumar, K., A. K. Sahai, K. Krishna Kumar, S. K. Patwardhan, P. K. Mishra, J. V. Revadekar, K. Kamala, and G. B. Pant, 2006: High-resolution climate change scenarios for India for the 21st century. Curr. Sci., 90, 334-345.

Shi, Y., 2010: A high resolution climate change simulation of the 21st century over East Asia by RegCM3 (in Chinese). Ph.D. dissertation, Chinese Academy of Sciences, $118 \mathrm{pp}$.

_- X. J. Gao, D. F. Zhang, and F. Giorgi, 2011: Climate change over the Yarlung Zangbo-Brahmaputra River Basin in the 21st century as simulated by a high resolution regional climate model. Quat. Int., 244, 159-168, https://doi.org/10.1016/j.quaint.2011.01.041.

Skamarock, W. C., and J. B. Klemp, 2008: A time-split nonhydrostatic atmospheric model for weather research and forecasting applications. J. Comput. Phys., 227, 3465-3485, https://doi.org/10.1016/j.jcp.2007.01.037.

Srinivas, C. V., D. Hariprasad, D. V. B. Rao, Y. Anjaneyulu, R. Baskaran, and B. Venkatraman, 2013: Simulation of the Indian summer monsoon regional climate using advanced research WRF model. Int. J. Climatol., 33, 1195-1210, https:// doi.org/10.1002/joc.3505.

_ D. V. Bhaskar Rao, D. Hari Prasad, K. B. R. R. Hari Prasad, Y. R. Baskaran, and B. Venkatraman, 2015: A study on the influence of the land surface processes on the southwest monsoon simulations using a regional climate model. Pure Appl. Geophys., 172, 2791-2811, https://doi.org/10.1007/ s00024-014-0905-9.

Tewari, M., and Coauthors, 2004: Implementation and verification of the unified Noah land surface model in the WRF Model. 20th Conf. on Weather Analysis and Forecasting/16th Conf. on Numerical Weather Prediction, Seattle, WA, Amer. Meteor. Soc., 14.2a, https://ams.confex.com/ams/pdfpapers/69061.pdf.

Tiedtke, M., 1989: A comprehensive mass flux scheme for cumulus parameterization in large-scale models. Mon. Wea. Rev., 117, 1779-1800, https://doi.org/10.1175/1520-0493(1989)117<1779: ACMFSF $>2.0 . \mathrm{CO} ; 2$.

Tiwari, P. R., S. C. Kar, U. C. Mohanty, S. Dey, S. Kumari, P. Sinha, P. V. S. Raju, and M. S. Shekhar, 2016: Simulations of tropical circulation and winter precipitation over north India: An application of a tropical band version of Regional Climate Model (RegT-Band). Pure Appl. Geophys., 173, 657-674, https://doi.org/ 10.1007/s00024-015-1102-1.

Varikoden, H., M. Mujumdar, J. V. Revadekar, K. P. Sooraj, M. V. S. Ramarao, J. Sanjay, and R. Krishnan, 2018: Assessment of regional downscaling simulations for long term mean, excess and deficit Indian Summer Monsoons. Global Planet. Change, 162, 28-38, https://doi.org/10.1016/j.gloplacha.2017.12.002.

Verma, R. R., T. K. Srivastava, and P. Singh, 2018: Climate change impacts on rainfall and temperature in sugarcane growing Upper Gangetic Plains of India. Theor. Appl. Climatol., 135, 279-292, https://doi.org/10.1007/s00704-018-2378-8.

Webster, P. J., V. O. Magaña, T. N. Palmer, J. Shukla, R. A. Tomas, M. Yanai, and T. Yasunari: 1998: Monsoons: Processes, predictability, and the prospects for prediction. J. Geophys. Res., 103, 14 451-14 510, https://doi.org/10.1029/97JC02719.

Wentz, F. J., 1997: A well-calibrated ocean algorithm for special sensor microwave/imager. J. Geophys. Res., 102, 8703-8718, https://doi.org/10.1029/96JC01751.

Xie, S. P., H. Xu, N. H. Saji, and Y. Wang, 2006: Role of narrow mountains in large-scale organization of Asian monsoon convection. J. Climate, 19, 3420-3429, https://doi.org/10.1175/ JCLI3777.1.

Yasunari, T., K. Saito, and K. Takata, 2006: Relative roles of largescale orography and land surface processes in the global hydroclimate. Part I: Impacts on monsoon systems and the tropics. J. Hydrometeor., 7, 626-641, https://doi.org/10.1175/ JHM515.1.

Yeh, T.-C., 1950: The circulation of high troposphere over China in winter of 1945-46. Tellus, 2, 173-183, https://doi.org/10.3402/ tellusa.v2i3.8548.

Zhang, D.-F., X.-J. Gao, H.-Z. Bai, and D.-L. Li, 2005: Simulation of climate over Qinghai-Xizang Plateau utilizing RegCM3 (in Chinese). Plateau Meteor., 24, 714-720. 